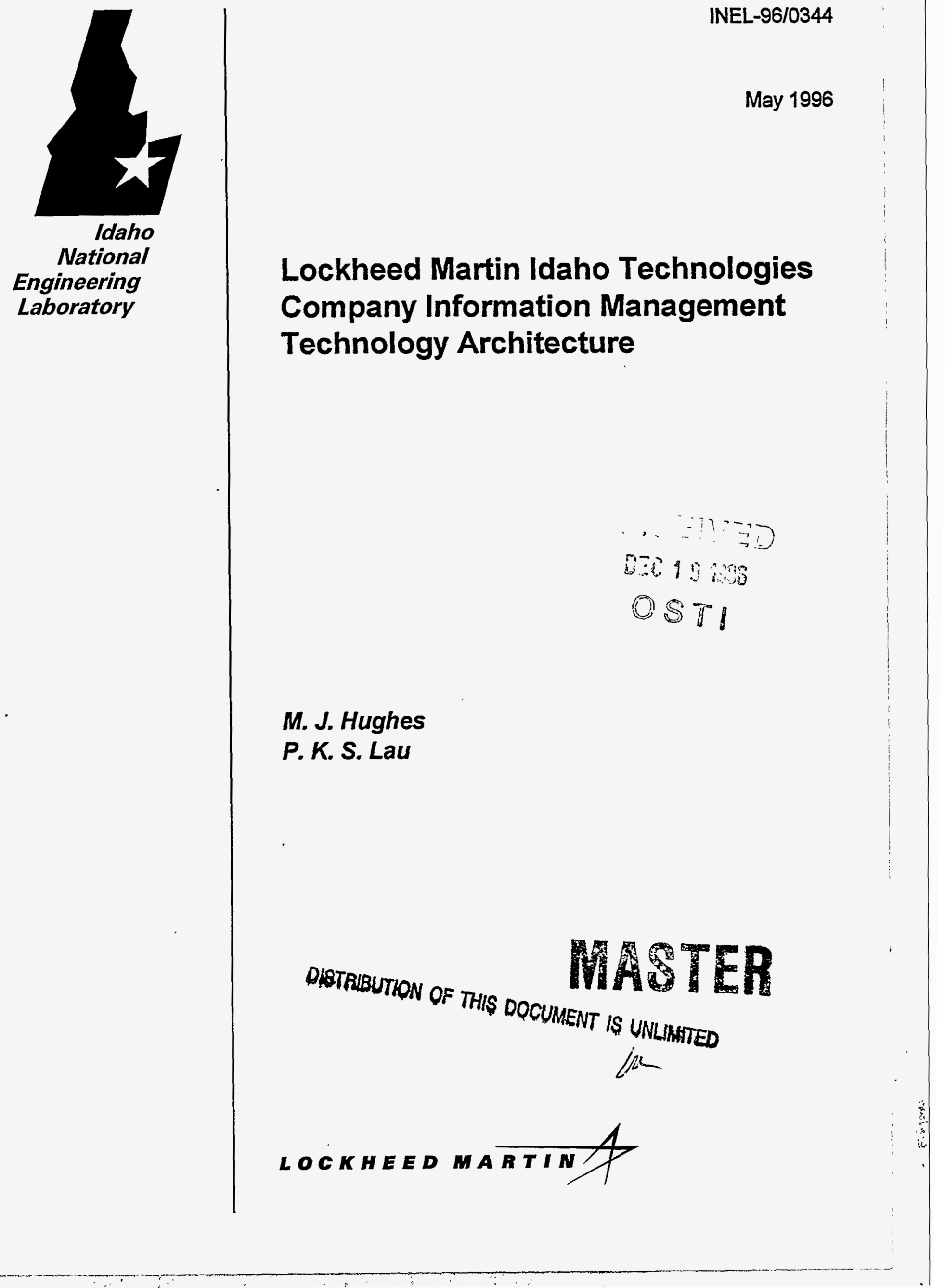




\section{DISCLAIMER}

Portions of this document may be illegible in electronic image products. Images are produced from the best available original document. 


\section{DISCLAIMER}

This report was prepared as an account of work sponsored by an agency of the United States Government. Neither the United States Government nor any agency thereof, nor any of their employees, makes any warranty, express or implied, or assumes any legal liability or responsibility for the accuracy, completeness, or usefulness of any information, apparatus, product, or process disclosed, or represents that its use would not infringe privately owned rights. Reference herein to any specific commercial product, process, or service by trade name, trademark, manufacturer, or otherwise does not necessarily constitute or imply its endorsement, recommendation, or favoring by the United States Government or any agency thereof. The views and opinions of authors expressed herein do not necessarily state or reflect those of the United States Government or any agency thereof. 


\title{
Lockheed Martin Idaho Technologies Company Information Management Technology Architecture
}

\author{
M. J. Hughes \\ P. K. S. Lau
}

Published May 1996

\section{Idaho National Engineering Laboratory Lockheed Martin Idaho Technologies Company Idaho Falls, Idaho 83415}

Prepared for the

U.S. Department of Energy

Under DOE Idaho Operations Office

Contract DE-AC07-94ID13223 


\section{Lockheed Martin Idaho Technologies Company Information Management Technology Architecture}

Approved By:

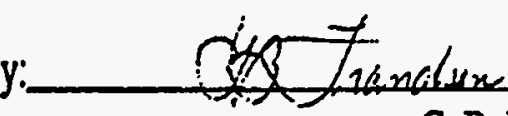

G. B. Frandsen

\%3r.36

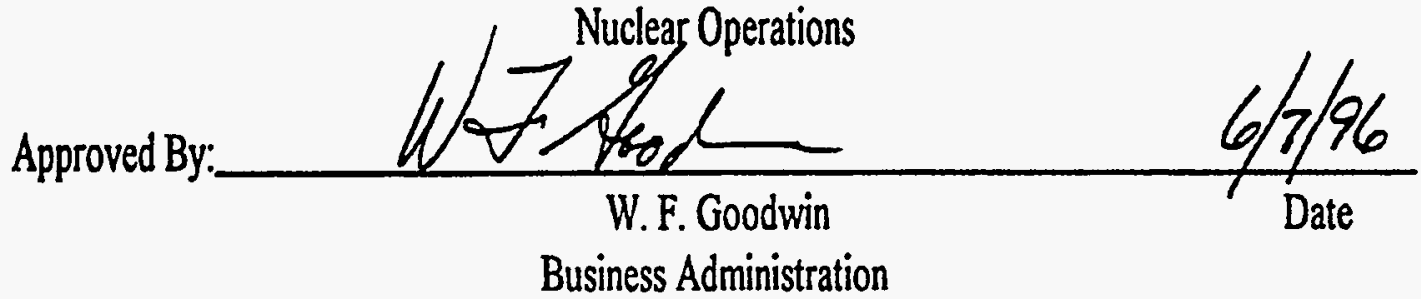

Approved By:- Q. ha - listh $\frac{6 / 9 / 96}{\text { A. M. Austin }}$

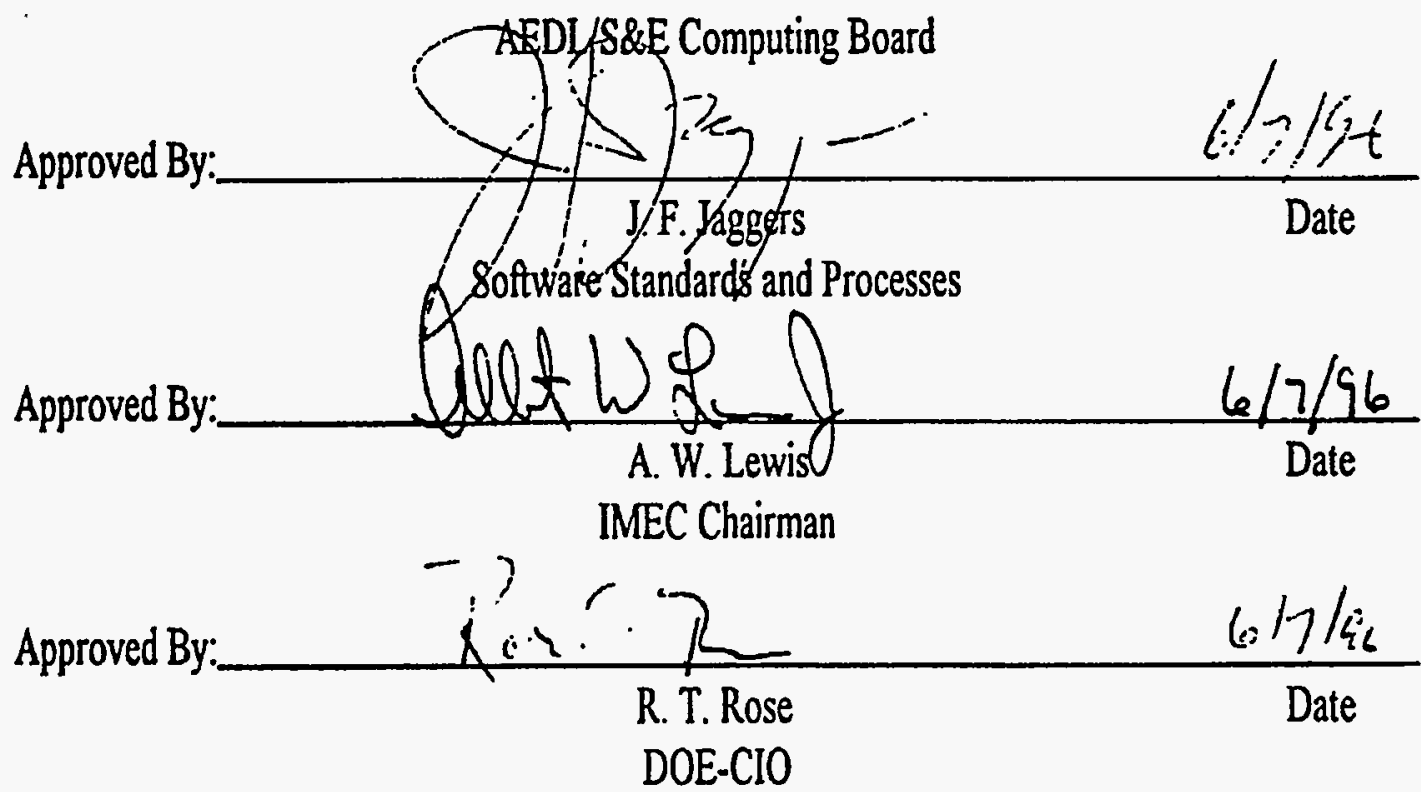

Approved By:- Lee deofby $\frac{1125144}{\text { S.A.Scobby }}$

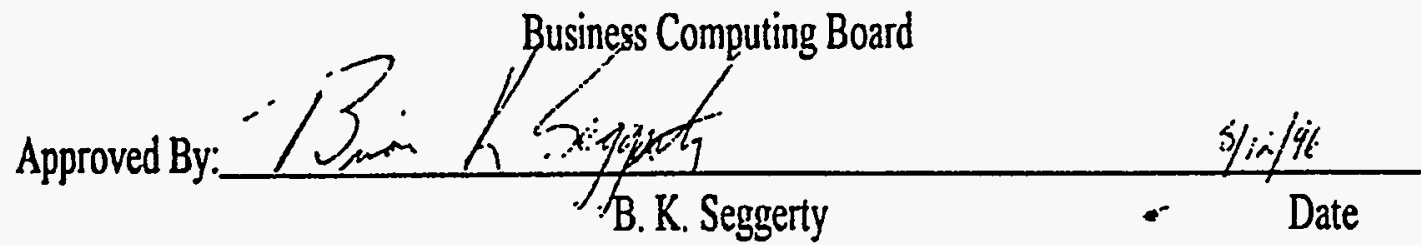
Environmental Operations

Approved By:

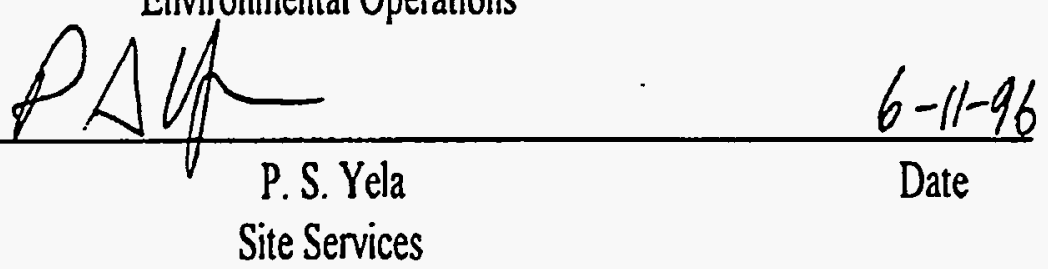




\section{CONTENTS}

ACKNOWLEDGMENTS $\ldots \ldots \ldots \ldots \ldots \ldots \ldots \ldots \ldots \ldots \ldots \ldots \ldots \ldots \ldots \ldots \ldots \ldots \ldots \ldots \ldots \ldots$

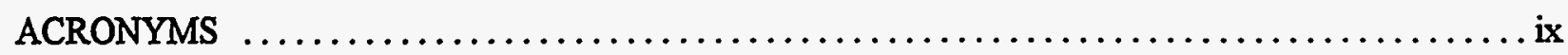

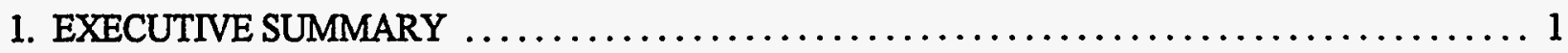

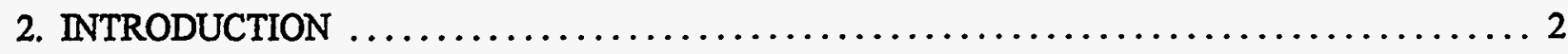

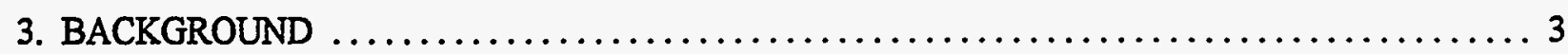

4. INFORMATION ARCHITECTURE $\ldots \ldots \ldots \ldots \ldots \ldots \ldots \ldots \ldots \ldots \ldots \ldots \ldots \ldots \ldots \ldots \ldots$

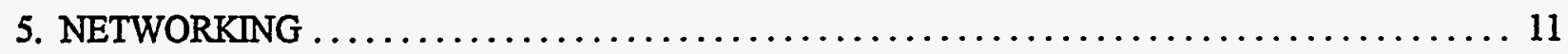

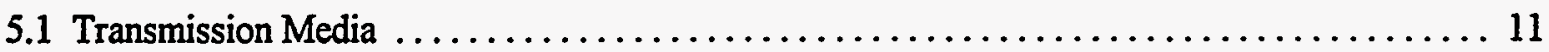

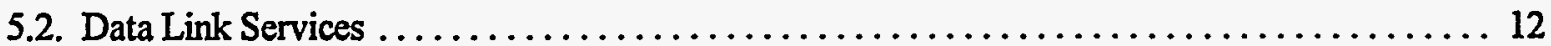

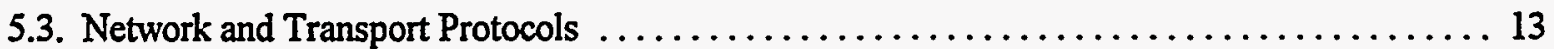

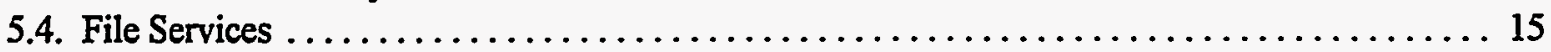

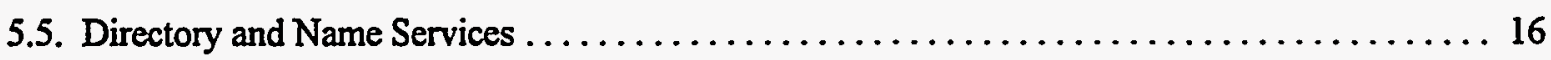

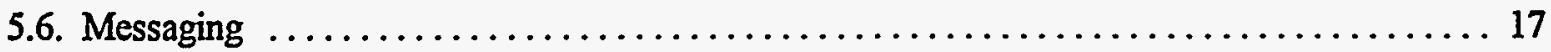

6. APPLICATION DEVELOPMENT TOOLS $\ldots \ldots \ldots \ldots \ldots \ldots \ldots \ldots \ldots \ldots \ldots \ldots \ldots \ldots \ldots \ldots$

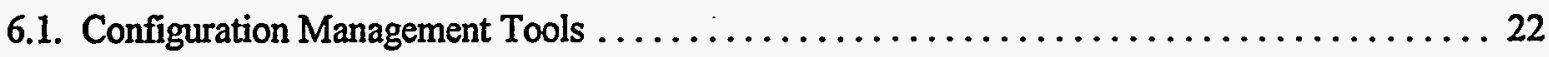

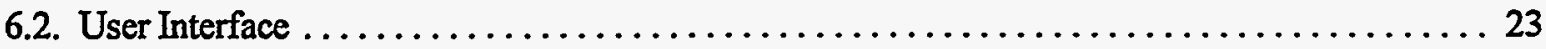

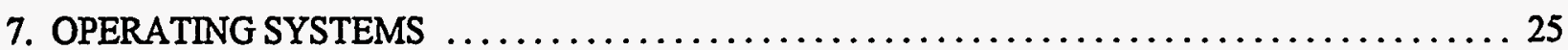

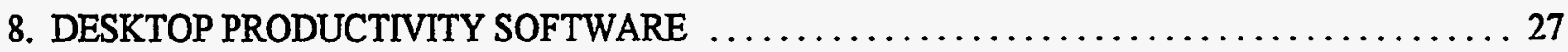

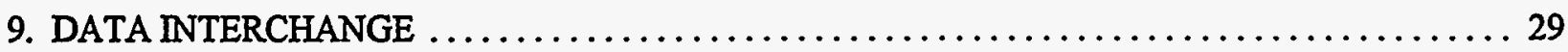

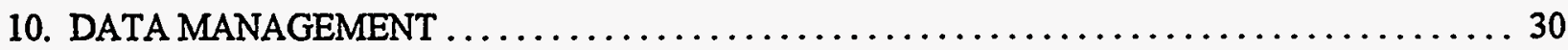

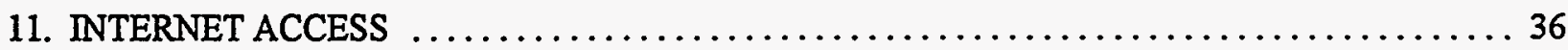

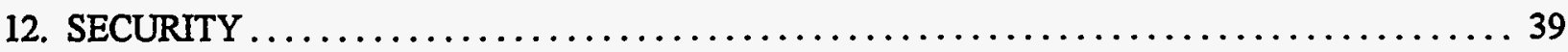

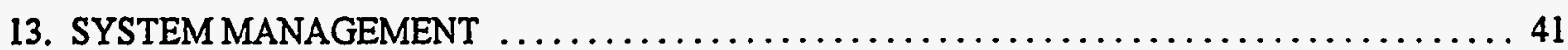
APPENDIX A 
FIGURES

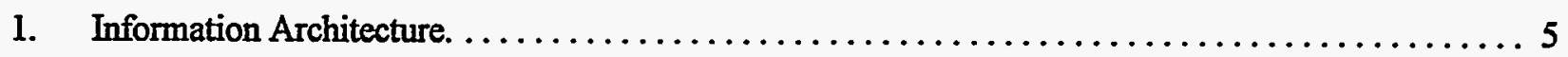

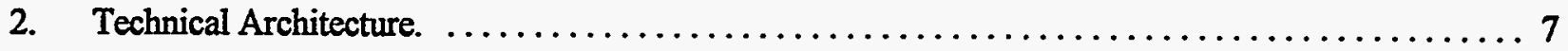

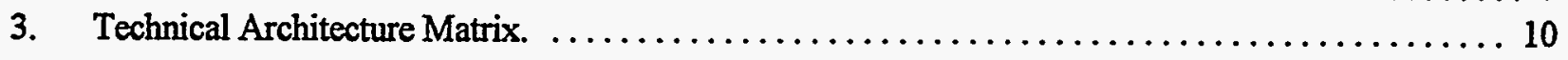




\section{ACKNOWLEDGMENTS}

\section{Core Team}

Mark J. Hughes

Philip K. S. Lau

Kellie L. Farrar

\section{Technical Area Teams}

Networking

William S. Jahsman (lead), Thomas J. Smith, Dave N. Tillitt, Dennis Carlson, Pat Rafferty

Application Development

Bran V. Heyrend (lead), William E. Lowrance, Brent Dixon, John Payne, Kent Klingler, Robert Smith, K.C. Lloyd, A.M. "Corky" Rohm

Operating Systems

Brent Dixon, Lynne Reeder, Rob Hoffman, Lloyd Clayton, J. Nick Curtis

Desktop Productivity Suite

Al Lewis Interdepartmental Communication Desktop Computer Software Suite Standard AWL-60-95

Data Interchange

Scott H. Harris (lead), Kevin Twitchell

Data Management

Robert E. Marshall (lead), Lloyd Clayton, Bill Bowman, John Wrablik, Kent Linsenmann, Dave Brown

Internet Access

A. M. "Corky" Rohm (lead)

Security

Larry L. Lightner (lead), Gene Reynolds 


\section{ACRONYMS}

3GLs

ACF2

ANSI

ANSI-FIPS

ATF

ATM

CAPS

CASE

CCF

CCITT

CERN

CGI

CICS

CICS/ESA

CMS

COTS

CPU

CSMA/CD

DB2

DBMS

DCE

DDL

DEC

DMCS

DML

DNS

DOE

DOE HQ

DOS

FDDI

FIPS PUB

FPROT

FTP

GSQL

GUI

HP

HTML

HTTP

IBM PC

ICASE

IEEE

IEF

IMEC
Third-Generation Language

Access Control Facility 2

American National Standards Institute

Federal Information Processing Standard

Appletalk Filing Protocol

Asynchronous Transfer Mode

Cost \& Planning System (INEL)

Computer Assisted Software Engineering

Change Control Facility

Consultive Committee for International Telephony and Telegraphy

European Laboratory for Particle Physics

Common Gateway Interface

Customer Information Control System (IBM)

CICS/ Extended Storage Architecture

Code Management System

commercial-off-the-shelf

Central Processing Unit

Carrier Sense Multiple Access with Collision Detection

Database 2 (IBM)

database management system

Distributed Computing Environment

Data Definition Language

Digital Equipment Corporation

Document Management Control System (INFL)

Data Manipulation Language

Domain Name Service

Department of Energy

Department of Energy Headquarters

Disk Operating System

Fiber Distributed Data Interface

Federal Information Processing Standard Publication

F-PROT

File Transfer Protocol

Gateway SQL

graphical user interface

Hewlett-Packard

HyperText Markup Language

HyperText Transport Protocol

International Business Machines Personal Computer

Integrated Computer Assisted Software Engineering

Institute of Electrical and Electronic Engineers

Information Engineering Facility

Information Management Executive Council 


\begin{tabular}{|c|c|}
\hline INMS & Integrated Materials Management System (INEL) \\
\hline MMPACT & Information Management Planning and Architecture Coordination Team \\
\hline INEL & Idaho National Engineering Laboratory \\
\hline INELNET & NEL Information Network \\
\hline INEL ADOC & Idaho National Engineering Laboratory Automated Document Control System \\
\hline $\mathbf{I P}$ & Internet Protocol \\
\hline IPX/SPX & Internet Packet Exchange/Sequenced Packet Exchange (Novell) \\
\hline IRDS & Information Resource Directory System \\
\hline IRM & Information Resource Management \\
\hline ISDN & Integrated Services Digital Network \\
\hline ISO/IEC & International Standards Organization/International Electrotechnical Commission \\
\hline ISS & Internet Security Scanner \\
\hline LAN & Local Area Network \\
\hline LMITCO & Lockheed Martin Idaho Technologies Company \\
\hline Lotus LMS & Lotus' Lotus Messaging System \\
\hline MOTIF & MOTIF \\
\hline MS Visual Basic & Microsoft Visual Basic \\
\hline MS Access & Microsoft Access \\
\hline MVS/ESA & multiple virtual systems/enterprise systems architecture \\
\hline MVS & multiple virtual systems \\
\hline NCP & Network Control Program \\
\hline NCSA & National Center for Supercomputing Applications \\
\hline NFS & Network File System \\
\hline NID & Network Intrusion Detection \\
\hline NIST & National Institute for Standards and Technology \\
\hline ODBC & Open Database Connectivity \\
\hline ODMG & Object Database Management Group \\
\hline ODS & Optical Data Systems \\
\hline OIM & Object Information Management \\
\hline OS & Operating System \\
\hline OS $/ 2$ & Operating System $/ 2$ \\
\hline OSF/DCE & Open Systems Foundation/Distributed Computing Environment \\
\hline РC/TCP & Personal Computer/Transport Control Protocol \\
\hline PECOS & Plant and Equipment Control System \\
\hline POSIX & Portable Operating System Interface for UNIX \\
\hline RDA & Remote Database Access \\
\hline SAG & SQL Access Group \\
\hline SATAN & Security Administrator Tool for Analyzing Networks \\
\hline SCCS & Source Code Control System \\
\hline SGML & Standard Generalized Markup Language \\
\hline SMTP/MIME & Simple Mail Transport Protocol/Multipurpose Internet Mail Extensions \\
\hline SNA & System Network Architecture (IBM) \\
\hline SPI & Security Profile Inspector \\
\hline SQL & Structured Query Language \\
\hline TA & Technology Architecture \\
\hline $\mathrm{TCP} / \mathrm{IP}$ & Transport Control Protocol/Internet Protocol \\
\hline
\end{tabular}


TI

UNICALL

UNIX

VM/ESA

VMS

VRML

VSAM

WAIS

WWW
Texas Instrument

Unified Budget Call

UNIX - operating system originally developed at AT\&T Bell Laboratories

Virtual Machine/Enterprise System Architecture

Virtual Memory System

Virtual Reality Modeling Language

Virtual Storage Access Method (IBM)

Wide Area Information Servers

World Wide Web 


\section{Lockheed Martin Idaho Technologies Company Information Management Technology Architecture}

\section{EXECUTIVE SUMMARY}

The Information Management Technology Architecture (TA) is being driven by the business objectives of reducing costs and improving effectiveness. The strategy is to reduce the cost of computing through standardization. The Lockheed Martin Idaho Technologies Company (LMITCO) TA is a set of standards and products for use at the INEL. The TA will provide direction for information management resource acquisitions, development of information systems, formulation of plans, and resolution of issues involving LMITCO computing resources. Exceptions to the preferred products may be granted by the Information Management Executive Council (IMEC).

The benefit in having a formal Technology Architecture is the ability to implement systems more rapidly at less cost. Other benefits include reduced software maintenance burden, more efficient technical support, increased allocation of "shadow" force time to primary functions, and as information systems are migrated to the target architecture, users will have convenient access to more information. Users will not have to be concerned with the physical location of information or complex technical details associated with the many technologies currently in use at LMITCO.

Certain implementation and deployment strategies are inherent in the design and structure of the LMITCO TA. These include (1) migration from centralized toward distributed computing; (2) deployment of the networks, servers, and other information technology infrastructure components necessary for a more integrated information technology support environment; (3) increased emphasis on standards to make it easier to link systems and to share information; and (4) improved use of the company's investment in desktop computing resources.

The intent is for the LMITCO TA to be a living document constantly being reviewed to take advantage of industry directions to reduce costs while balancing technological diversity with business flexibility.

This document does not yet address COTS functional applications (e.g. Auto CAD), custom built applications (e.g. RELAP5), or display formats. 


\section{INTRODUCTION}

To ensure continued mission success within the Department of Energy, LMITCO must respond successfully to the same competitive challenges being faced by organizations throughout the world. These challenges include increasing worldwide competition for new and existing markets, unprecedented cost and quality competition, uncertain and dynamic fiscal environment, and a rapidly changing technology base.

Important management objectives for any company are to become more technologically integrated and business flexible. The term "Single System Image" has been used to convey the sense of this objective. The realization of this objective is necessary to succeed in a business environment that places a premium on flexibility and responsiveness. The company must be able to take advantage of its people, resources, and technologies as business opportunities arise. The physical or organizational location of people and other resources should not present a barrier in responding to these opportunities.

In today's dynamic business and technical environment, the effective management and use of information can directly influence the competitive position of any organization. Throughout industry, managers have become increasingly aware of the vital importance of sound information management practices and the need to maintain an effective linkage between the company's business strategies and its information management strategies. Without the existence of a sound technology architecture, an organization will operate at a significant competitive disadvantage.

Communications is the key to achieving this objective. A well defined technology architecture facilitates the prompt flow of accurate information required for effective decisions. The development of such an architecture is a complex challenge that provides guidance to individuals and development teams as they acquire information technology resources, develop information systems, design networks, and make decisions that affect the technology architecture. An important implementation objective of the LMITCO TA is to make everyone want to use it because of its benefit. The success of this document and the company's competitive advantage is directly related to how this document is used.

The primary benefit of the LMITCO TA will be the development of a cost effective technical infrastructure. This infrastructure will support LMITCO in being more competitive. In addition, as applications are developed using the LMITCO TA as guidance, users will have access to a broader range of information sources. Users will not have to be concerned with the physical location of the information.

LMITCO is committed to a Technology Architecture that is based on industry standards towards open systems where economically feasible. In addition, LMITCO will emphasize using commercial-off-the-shelf products where practical and cost effective. The Technology Architecture supports a user centric ideology reflecting a client/server distributed computing architecture with graphical user interfaces over a network that connects anyone compliant to the LMITCO Technical Architecture. The LMITCO TA is a key element of the overall information management process necessary to achieve mission success within the Department of Energy. 


\section{BACKGROUND}

With the contract award to Lockheed to manage the Idaho National Engineering Laboratory (INEL) and the Department of Energy (DOE) facing fiscal reductions, it is imperative that a different approach to information management be implemented. The change was felt in a new planning process initiated in FY95 for the FY97 Unified Budget Call (UNICALL). This was the primary focus for the DOE Information Management Planning and Architecture Coordination Team (IMPACT), which met in the fall of 1994 in Idaho Falls.

As part of the meeting in Idaho Falls, another effort was started to define a process for developing the DOE's Information Architecture. DOE's Technology Subarchitecture was further defined in May 1995 resulting in candidate standards focusing on connectivity and interoperability. The candidate standards are available on the web at $h t t p: / / w w w . i n e l . g o v: 80 / i m p a c t / i m p a c t / c o n t e n t s . h t m l$. Consensus was obtained for Department of Energy Headquarters (DOE HQ) to provide standard guidelines and not name products. Product selection would be left to local authorities. The standards guideline is scheduled to be approved and announced in FY96.

Another major event, the merger of Lockheed and Martin Marietta, also initiated a standardization effort that will address products for the Lockheed Martin family. Product guidelines will be forth coming periodically through FY96.

The LMITCO TA will look to the DOE for standards and Lockheed Martin for products to guide LMITCO selections. Where conflict arises between the DOE standard and Lockheed Martin product guidelines the DOE standard will carry more weight. Product selection decisions will be made by business factors at LMITCO.

The intent of this initial technology architecture is to establish a baseline. The TA will mature over time as inputs from DOE and Lockheed Martin are received and as industry matures. Where the industry is immature, the LMITCO TA attempts to document the current situation at LMITCO.

The process used to create this initial base line relied on the support of current providers in the company. A survey was conducted to identify what existed in the company. The results, summarized in letter Result of Technology Architecture Survey-PKL-04-95, were used as input by the "experts" to create this draft LMITCO TA. The draft was then distributed to members of the Information Management Executive Council (IMEC) for their constituents review and comments. Upon reconciling these comments, the Information Management Executive Council (IMEC) sanctioned use of the LMITCO TA.

Although applications such as Cost and Planning System (CAPS), Integrated Materials Management System (IMMs), Plant and Equipment Control System (PECOS), Document Management Control System (DMCS), etc. are part of the Technology Architecture, it was deemed premature to address applications without significant portions of the Information Architecture being in place. 


\section{INFORMATION ARCHITECTURE}

In order to understand the role of the Technology Architecture, the concept and approach for an Information Architecture, certain words and terms must have an agreed upon meaning or definition.

The objective of designing and implementing an Information Architecture is to promote understanding and utilization of information by relating appropriate enterprise information through functions, processes, and activities. The Information Architecture should serve as a "tool" to understand, organize, and utilize information.

The Information Architecture (Figure 1) consists of four layers: Information Infrastructure, Enterprise Architecture, Business Systems Architecture, and Technology Architecture. The Information Infrastructure describes and documents the management infrastructure needed to direct the enterprise's Information Architecture activities. The Enterprise Architecture describes and documents what work is performed. The Business System Architecture describes and documents how work is performed. The Technology Architecture describes and documents the technologies and automated systems that support the performance of work. Information contained in each layer is based upon and is the basis for information in other layers. For a more detailed explanation of the Information Architecture, see Lockheed Martin Idaho Technologies Information Architecture Strategy Project Concept and Approach, INEL-95/0265, May 1995.

\section{Technology Architecture}

The Technology Architecture contains information about computer software, hardware, and communications components required to provide an environment that supports automated systems in performing their tasks. The Technology Architecture describes the structure required to perform an enterprise's work in terms of automated systems which support manual processes. The hardware platforms are described in Appendix A. The Technology Architecture provides direction:

- To users and information management professionals to aid in the selection and use of information technologies and products

- To project teams designing and deploying automated systems

- To technology planners developing an enterprise's information technology infrastructure

- For development of long-term implementation and migration strategies for key business focus areas, such as major production business systems or key service functions, such as electronic mail. 


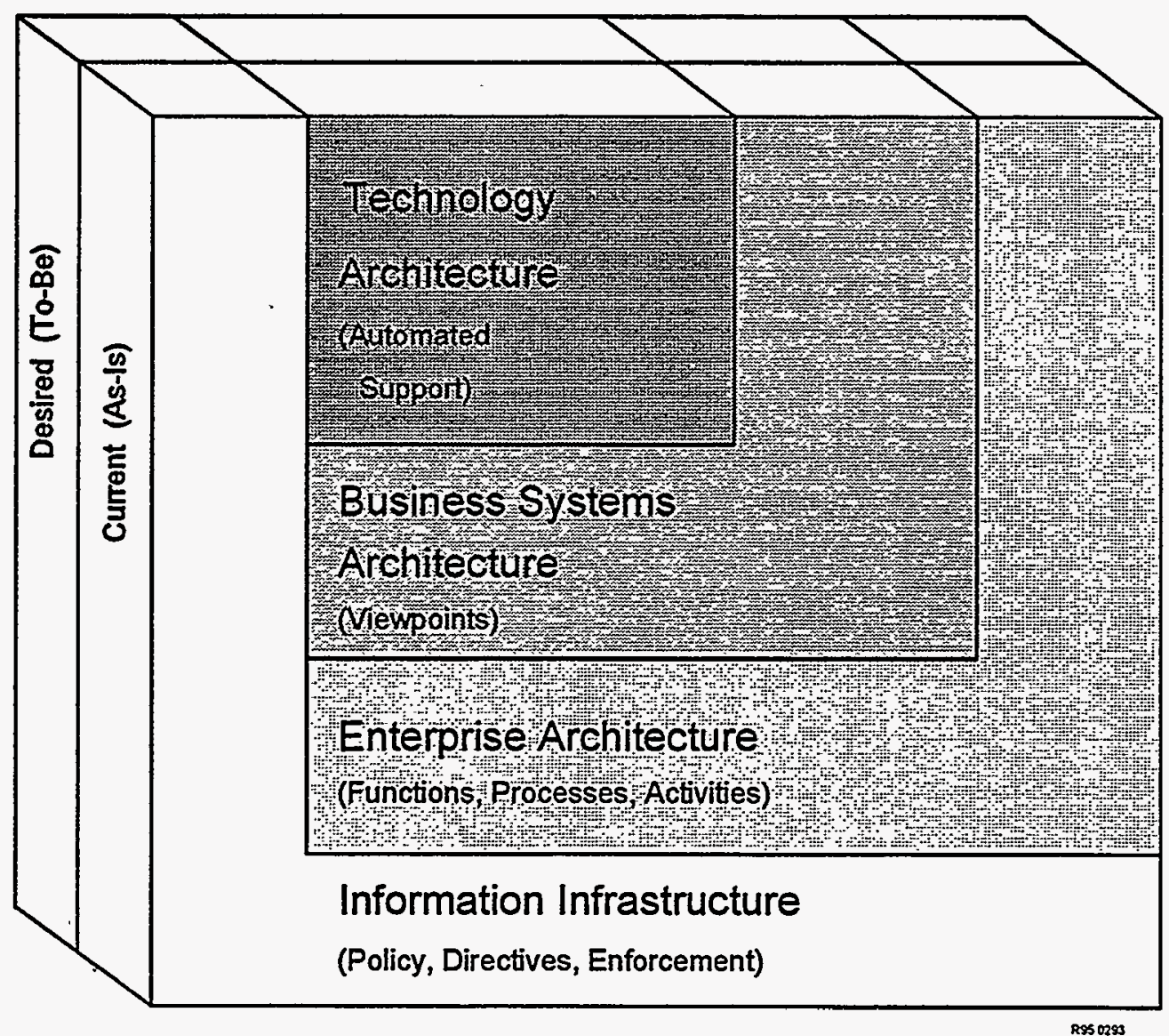

Figure 1. Information Architecture. 
The purchase of commercial, off-the-shelf (COTS) software raises a special concern in meeting the criteria in the technology architecture. COTS software is expected to conform to the guidelines listed herein. However, the selection and use of COTS software is both an economic and a technical decision. There might be circumstances where non-conforming COTS software would be a viable option. All relevant considerations should be taken into account as these decisions are made.

This document does not yet address COTS functional applications (e.g. Auto CAD), custom built applications (e.g., RELAP5), or display formats.

Figure 2 depicts the service areas for the LMITCO TA. The service areas are explained in the following paragraphs.

Networking: Provides the capabilities and mechanisms to support distributed applications requiring data access and applications interoperability in heterogenous networked environments. Components of this category include data communications, messaging, directory services and file services.

Application Development: The tools used to develop and maintain computer-based applications. The choice of tools and methods can have a significant impact on initial development and ongoing maintenance costs. The general strategy in this area is to develop open applications (i.e., those that have portability, scalability, and interoperability), and to use the highest level tools available to optimize the time of application system developers. These include languages, tools, and user interfaces.

Operating Systems: Operating systems provide the core services necessary to execute and administer application systems running on computing platforms. These systems also provide an interface between applications software and the computing platform. Operating system services include the subcomponent functions of kernel operations, system administration commands and utilities, system management, and system backup.

Desktop Productivity Software: Provides the software tools that allow individual users within the company to accomplish their day-today business functions efficiently and effectively. These tools usually include word processing, spreadsheet analysis, presentation package, calendaring, and a database product.

Data Interchange: Data Interchange provides specialized support for the exchange of information, including format and semantics of data entities, between applications on the same or different platforms. Components of this category include text data, spreadsheet data interchange, desktop publishing interchange, graphics interchange, image compression/decompression, and calendar data. Other types could include geospatial or geographical data and specialized or scientific data.

Data Management: Provides the functions to establish data dictionaries and data directory services, database management systems, and access to distributed data. Central to most systems is the management of data that can be defined independently of the processes that create or use that data, maintained indefinitely, and shared among many processes. This encompasses the procedures, practices, methods, and software used to manage data. Components of this category include data dictionary/directory, database management system, and distributed data. 


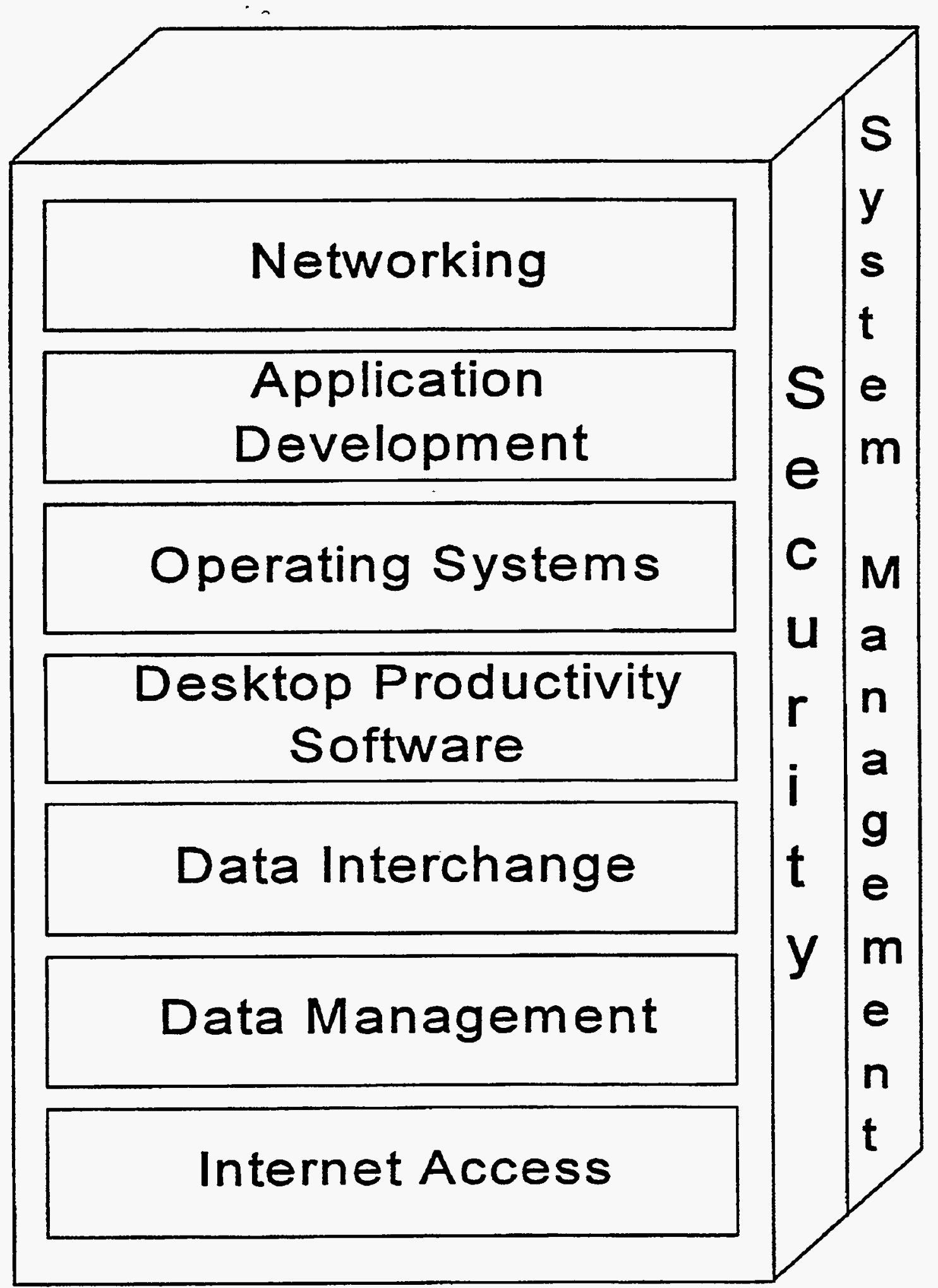

Figure 2. Technical Architecture. 
Internet Access: Provides the tools that allow for viewing information on, as well as downloading data specific to the objectives of LMITCO from the Internet (e.g., the World Wide Web). This includes the tools that allow development of information that can be made accessible on internal or external home pages.

Security Area (Crosscutting): Provides support distribution and integrity of data and protects the computing infrastructure from unauthorized access at all levels. Security services support the secure distribution and integrity of information and protect the computing infrastructure from unauthorized access. These services control access to data, functions, software, and hardware. The security services also provide confidentiality through encryption techniques, integrity, auditing, and electronic signatures. Components of this category include operating system security, network security, data interchange security, and data management security.

System Management Area (Crosscutting): Provide the mechanisms to monitor and control the operation of individual applications, databases, systems, platforms, networks, and user interactions with these components at all levels. Management services are integral to the operation of an open system environment. They provide the mechanisms to monitor and control the operation of individual applications, databases, systems, platforms, networks, and user interactions with these components. Management services enable users and systems to become more efficient in performing required work. Components of this category include fault management and control, configuration, accounting, and performance.

\section{Technology Architecture Matrix}

The TA is in the form of a matrix (Figure 3) keyed to supporting narrative documentation. The objective of the matrix is to organize the components of a typical TA in a way that facilitates analysis, planning, communication, and use. In actual practice and in terms of physical implementations, the components of a TA are interrelated and interconnected in highly complex ways. The TA attempts to abstract these components into a simplified model to allow strategies, options, and issues to be communicated more effectively.

The matrix is defined by tiers: tier 1 being the client platforms used at LMTCO (PC, Macintosh, and (NNIX) and tier 2 being servers regardless of size. Within each tier the cells contain various standards, preferred products, and supported products. These are defined as follows:

Standard: A standard can be classified as a set of specifications. The most likely source of potential standards are those already developed and widely accepted within industry, which have proven their benefit through the test of time. Adoption of such standards would facilitate interoperability not only within LMITCO but also with the external community. In lieu of the availability of appropriate external standards, LMITCO should choose to adopt already widely used protocols and tools as de facto, consensus-based standards.

Preferred Product: This designates products that are "allowed to be purchased" and supported within LMITCO. Use of preferred items will contribute to the orderly migration of the existing systems toward LMITCO's overall Information Management vision. Moreover, selection and use of preferred products will potentially save the user time and money. 
Supported Product: This identifies products that are supported company wide. Company wide support means an organization will provide support to anyone in the company. This does not necessarily mean the support will be provided at no charge. Support includes but is not limited to help with using the product, standard configuration, data conversion, and ensuring compatibility between supported products.

Note: An information system designer will want to examine both the standard and preferred categories carefully to make a fully informed decision. There may be instances when the prudent course of action would be to wait or perhaps to design a minimal system pending the acquisition of a preferred product, the availability of which is imminent. 


\begin{tabular}{|c|c|c|c|c|}
\hline & \multicolumn{3}{|c|}{ Tier 1} & Tier 2 \\
\hline & PC & $\mathrm{MAC}$ & UNIX & Server \\
\hline Standard & & & & \\
\hline $\begin{array}{l}\text { Preferred } \\
\text { Product }\end{array}$ & & & & \\
\hline $\begin{array}{c}\text { Supported } \\
\text { Product }\end{array}$ & & & & \\
\hline
\end{tabular}

Figure 3. Technical Architecture Matrix. 


\section{NETWORKING}

\section{Overview}

Network services include wiring and protocol specifications to enable reliable, transparent, end-to-end data transmission across communications networks; transparent file access to local and remote files; and microcomputer support for the interoperability of proprietary systems. Elements of network services include.

- Transmission media

- Data link services

- Network and transport protocols

- $\quad$ File services

- Directory and naming services

- Network management

- Messaging

\subsection{Transmission Media}

The network infrastructure must be flexible enough to support continuing increases in the power and speed of desktop systems. Networking bandwidth is being pushed higher to meet this challenge. Extending the bandwidth horizon requires careful planning and selections of media and infrastructure.

\begin{tabular}{|l|l|c|}
\hline & \multicolumn{1}{|c|}{ LAN } & \multicolumn{1}{|c|}{ Backbone } \\
\hline Standard & $\begin{array}{l}\text { Cat 5 unshielded twisted Pair (24 } \\
\text { AWG); 62.5/125 micron multimode } \\
\text { fiber }\end{array}$ & 9 micron single mode fiber \\
\hline $\begin{array}{l}\text { Preferred } \\
\text { Products }\end{array}$ & $\begin{array}{l}\text { Cat 5 unshielded twisted pair (24 } \\
\text { AWG); 62.5/125 micron multimode } \\
\text { fiber }\end{array}$ & 9 micron single mode fiber \\
\hline $\begin{array}{l}\text { Supported } \\
\text { Products }\end{array}$ & \multicolumn{1}{|c|}{ AT\&T and Siecor Products } \\
\hline
\end{tabular}




\section{Standard}

The Local Area Network (LAN) standard consists of EIA 568 standard Category 5 unshielded twisted pair. This is an industry standard for copper media that can be used for both voice and data in an office area. The LAN standard also consists of multimode fiber optic cable. The standard employs the most widely used inside diameter/outside diameter multimode fiber (62.5/125 micron). Multimode fiber - is excellent for use in a building and campus environment.

The Backbone standard is 9 micron single mode fiber. Single mode fiber is designed for long haul transmission as it is designed to maintain signal quality over long distances.

\section{Preferred Products}

Industry is designing the next generation of products to operate on these media. Expect to see $10 \mathrm{Gbps}$ transmission rates on single mode fiber and up to $622 \mathrm{Mbps}$ on multimode fiber and Category 5 copper wire.

\section{Supported Products}

LMITCO uses AT\&T and Siecor fiber and fiber termination products. For cable and cable terminations LMITCO uses AT\&T Systimax Category 5 products. These products meet the highest standards in the industry and are available from a great number of sources of supply at competitive prices.

\subsection{Data Link Services}

The data link layer of a network architecture ensures effective physical transfer of data between network nodes.

\begin{tabular}{|l|l|l|}
\hline & \multicolumn{1}{|c|}{ Client/Server } & \multicolumn{1}{|c|}{ Network Devices (hubs) } \\
\hline Standard & \multicolumn{1}{|c|}{ Ethernet II, IEEE 802.3, ANSI X3T9.5 } \\
\hline $\begin{array}{l}\text { Preferred } \\
\text { Products }\end{array}$ & \multicolumn{2}{|c|}{ TBD } \\
\hline $\begin{array}{l}\text { Supported } \\
\text { Products }\end{array}$ & $\begin{array}{l}\mid c / 100 \text { Mbps Ethernet interface } \\
\text { cards, } \\
100 \text { Mbps FDDI cards }\end{array}$ & $\begin{array}{l}\text { Ungermann-Bass, David Systems, } \\
\text { Optical Data Systems, Cisco }\end{array}$ \\
\hline
\end{tabular}

\section{Standard}

The Institute of Electrical and Electronic Engineers (IEEE) 802.2 Standard defines logical link control. The following multiple standards have been defined for media access control:

1. Ethernet Standard II (Digital Equipment Corporation (DEC), Intel, Xerox), published 1982, 
2. IEEE 802.3 for Carrier Sense Multiple Access with Collision Detection (CSMA/CD) used primarily for Ethernets,

3. American National Standards Institute (ANSI) X3T9.5 for Fiber Distributed Data Interface (FDDI).

In addition to defining the media access control, standards 1 and 2 above describe different format and framing of packets for Ethernet-based networks. Ethernet Version 2 has the greatest acceptance by industry, offers greater flexibility than 802.3 , and, therefore, represents the "target."

\section{Preferred Products}

Asynchronous Transfer Mode (ATM) technology appears to be a natural successor to FDDI in the LAN environment and to narrowband Integrated Services Digital Network (ISDN) as well. The Cisco and Optical Data Systems (ODS) products will also support integrated ATM modules. There is a process underway that is evaluating high-end switching hub-ATM switches to recommend a product that supports the ATM standard.

\section{Supported Products}

LMITCO supports 3Com 1OBaseT network interface cards and Sun, DEC, Hewlett-Packard (HP), SGI and International Business Machines (IBM) FDDI cards for clients and servers. Network hubs are provided by $\mathrm{Cisco}$ (the 1202 and 5000 series switching hub products and the 7000 series routers), David Systems, Optical Data Systems (ODS) for distribution of FDDI interfaces, and Ungermann-Bass, a legacy system 1OBaseT (and pre-1OBaseT) interface provider. The David Systems and Ungermann-Bass devices will be phased out as funds are available.

\subsection{Network and Transport Protocols}

A network-level interconnection provides a mechanism that delivers packets from their original source to their ultimate destination in real time - it maps directly onto the underlying network hardware. Second, it separates data communication activities from application programs, permitting machines to handle network traffic without understanding the applications that use it. (Comer, 1991)

The transport layer provides end-to-end communication from one application to another. It sits between the application and the network. It may perform such tasks as regulating the flow of information, providing reliable transport, and accepting data from several applications. (Note: Internet Protocol (IP) and Apple Corp. products in this category include some upper layer protocols.) 


\begin{tabular}{|l|l|l|l|l|}
\hline & \multicolumn{3}{|c|}{ Client } & \multicolumn{1}{|c|}{ Server } \\
\hline Standard & \multicolumn{3}{|c|}{ Internet Protocol Suite (TCP/IP) } \\
\hline $\begin{array}{l}\text { Preferred } \\
\text { Products }\end{array}$ & \multicolumn{3}{|c|}{ TBD } \\
\hline $\begin{array}{l}\text { Supported } \\
\text { Products }\end{array}$ & \multicolumn{3}{|c|}{ PC } & \multicolumn{3}{|c|}{ MAC } & UNIX & $\begin{array}{l}\text { Appletalk2, Novell } \\
\text { IPX/SPX, DECnet } \\
\text { Phase IV, IBM SNA, } \\
\text { TCP/IP }\end{array}$ \\
& $\begin{array}{l}\text { Sun's PC-NFS, } \\
\text { Netmanage } \\
\text { Chameleon NFS } \\
\text { TCP/P, Novell } \\
\text { IPX/SPX, IBM SNA, } \\
\text { FTP Software } \\
\text { PC/TCP, Novell } \\
\text { LAN Workplace for } \\
\text { DOS }\end{array}$ & $\begin{array}{l}\text { Appletalk, MAC } \\
\text { IP, Novell } \\
\text { IPX/SPX }\end{array}$ & $\begin{array}{l}\text { DECnet Phase } \\
\text { IV, Internet } \\
\text { Protocol Suite }\end{array}$ & \\
\hline
\end{tabular}

\section{Standard}

The Internet Protocol Suite refers to a collection of programs that provide application to network layer services. Because of its availability and interoperability, the Transport Control Protocol/Internet Protocol (TCP/IP) suite has become the de facto standard throughout industry.

\section{Preferred Products}

The next version of IP (dubbed IP next generation, or IPng) will resolve addressing limitations in the current version. LMITCO will analyze the situation and select products that support the desired technology.

\section{Supported Products}

This is the baseline technical architecture document. As tactical plans are developed to migrate to the preferred product, a summary of the strategy will appear in this section. 


\subsection{File Services}

File services provide transparent remote on-line access to shared files across the network.

\begin{tabular}{|c|c|c|c|c|}
\hline & \multicolumn{3}{|c|}{ Client } & Server \\
\hline Standard & \multicolumn{4}{|c|}{ NFS (RFC 1094); FTP } \\
\hline $\begin{array}{l}\text { Preferred } \\
\text { Products }\end{array}$ & \multicolumn{4}{|c|}{ TBD } \\
\hline \multirow[t]{2}{*}{$\begin{array}{l}\text { Supported } \\
\text { Products }\end{array}$} & $\mathrm{PC}$ & MAC & UNIX & \multirow{2}{*}{$\begin{array}{l}\text { Novell NCP, Appletalk ATF, Various } \\
\text { FTP, Sun's NFS, Novell, NT file } \\
\text { services using TCP/PP } \\
\end{array}$} \\
\hline & $\begin{array}{l}\text { Sun's NFS, Various } \\
\text { FTP, Novell }\end{array}$ & $\begin{array}{l}\text { Sun's, } \\
\text { NFS, } \\
\text { Various } \\
\text { FTP, } \\
\text { Novell }\end{array}$ & $\begin{array}{l}\text { Sun's } \\
\text { NFS, } \\
\text { Various } \\
\text { FTP }\end{array}$ & \\
\hline
\end{tabular}

\section{Standard}

Sun's Network File System (NFS) is the de facto distributed file system for the UNIX operating system environment. NFS is widely used today, but it lacks scalability and critical security features. It also lacks a consistent directory structure.

File Transfer Protocol (FTP) represents a widespread means of distributing and exchanging files across all three tiers (via TCP/IP) and FTP client software is readily available for all tiers. When only Macintosh-based systems need to share information, servers using AppleTalk Filing Protocol (ATF) are often deployed.

\section{Preferred Products}

TBD

\section{Supported Products}

NFS, a protocol developed by Sun Microsystems, uses IP to allow a set of cooperating computers to access each other's file systems as if they were local. The key advantage of NFS over conventional file transfer protocols is that NFS hides the differences between local and remote files by placing them in the same name space. NFS was designed for UNIX systems, but has been implemented on many other systems, including personal computers like the IBM PC and Apple Macintosh.

Novell (netware file services) supports DOS, Unix, Macintosh, and OS/2 operating systems. Volumes can be configured for long file name support. File grooming allows deleted files to be recovered and aged files to be compressed for storage or migrated to secondary storage media. File security can be administered at the individual file level or across the enterprise. 
Microsoft Windows NT file services support DOS, Unix, Macintosh, and O/S2 operating systems. The file and directory names can be up to 255 characters in length. NT offers auto-recovery in the event of system failure. File security is rudimentary and is based upon group level access control.

\subsection{Directory and Name Services}

Directory services and name services provide the capability to locate people, resources, and information and to translate human names into forms that are useful to computer software. A directory service is a service analogous to a telephone directory, and as such contains information helping to identify, locate, and access entities. Typical resources are users, platforms, and RPC-based services; attributes of those resources include the name, the address of a server, or a user's home directory address. Directory services rely upon "name services" to uniquely identify objects.

The goal of LMITCO's directory and name services is to provide location independence and authenticate access to corporate (and possibly external) data. To achieve this goal two types of service are needed--global services and local services company-wide.

Local services can be viewed as cell-based, where a cell could be defined as all of LMITCO or one site or one building or one project. Global services link local services. To be effective the two services must interoperate and the boundary between the cell and global services must be set to provide appropriate performance levels.

\begin{tabular}{|l|l|l|}
\hline & \multicolumn{1}{|c|}{ Client } & \multicolumn{1}{c|}{ Server } \\
\hline Standard & \multicolumn{2}{|c|}{ X.500 } \\
\hline $\begin{array}{l}\text { Preferred } \\
\text { Products }\end{array}$ & \multicolumn{2}{|c|}{ TBD } \\
\hline $\begin{array}{l}\text { Supported } \\
\text { Products }\end{array}$ & $\begin{array}{l}\text { DNS, YP (NIS), NIS+, WINS, } \\
\text { MS TCP/IP }\end{array}$ & DNS, YP (NIS), NIS+, WINS \\
\hline
\end{tabular}

\section{Standard}

On the global scale, X.500 services are beginning to become available. The Distributed Computing Environment (DCE) Naming and Directory Services provide both global (X.500) and local support integrated with Security Services, Threads, and RPC support. DCE also supports the Domain Name Service (DNS) for global directory services.

While the above services represent the current target, it remains to be seen whether or not there will be commercial products which implement these services as defined by the standards bodies. Until then, it is likely that LMITCO will be using a multitude of directory services, one per functional area (e.g., one for resolving IP addresses, another for locating LAN file and printer services, another for E-mail systems, another for database systems, etc,). 


\section{Preferred Products}

TBD

\section{Supported Products}

This is the baseline technical architecture document. As tactical plans are developed to migrate to the preferred product, a summary of the strategy will appear in this section.

\subsection{Messaging}

Electronic mail (E-mail) describes a service which facilitates communication by providing computer users the capability to send and receive information (audio, video, text, images, etc.) electronically.

The use of E-mail speeds communication, conserves resources, and enables users to be more productive. It is the most widely used computer service in LMITCO and is critical to the execution of daily business. Its routine use is rapidly evolving from text-only messages to complex multimedia messages including images, video, and audio.

The primary objective of the company's E-mail strategy is to integrate all supported systems into a single logical messaging network. Users should not be required to know which E-mail system others use in order to compose a message that can be used effectively by all intended recipients. In order to meet this objective, open, vendor-neutral communication protocols and message formats are required. Another E-mail strategy is migration from large central computers toward networked, distributed systems in order to more effectively utilize desktop computing resources, provide better integration of electronic mail with other desktop applications, and provide interfaces which are in many instances, easier to use and provide functionality better matched to the needs of individual users.

\begin{tabular}{|l|c|c|}
\hline & Client & Server \\
\hline Standard & \multicolumn{2}{|c|}{ SMTP/MMME, X.400 } \\
\hline $\begin{array}{l}\text { Preferred } \\
\text { Products }\end{array}$ & Lotus' LMS \\
\hline $\begin{array}{l}\text { Supported } \\
\text { Products }\end{array}$ & cc:Mail, Office Vision, Eudora, ELM, POP, Notes Mail \\
\hline
\end{tabular}

\section{Standard}

Three alternatives are available: Consultive Committee for International Telephony and Telegraphy (CCITT) X.400 and the Internet Protocol Suite; the latter usually being referred to by its two most prominent messaging protocols, Simple Mail Transport Protocol/Multipurpose Internet Mail Extensions (SMTP MIME). SMTP MIME provides better external connectivity and experience has shown that available $X .400$ products are less mature, more expensive, and considerably more difficult to manage, LMITCO will have it E-mail connectivity strategy on SMTPMIME and X. 400. 
Most external sites that use X.400 also operate gateways to Internet SMTP/MIME-based E-mail systems, including the public X.400 service providers (e.g., AT\&T, MCI, Sprint).

MAPI is also an alternative that may become a viable standard in the future, but is not an accepted standard as of yet. MAPI is a set of API functions and Microsoft OLE 2.0 Component Object Model (COM) interfaces that messaging applications use to create, manipulate, transfer, and store messages.

MAPI helps applications define the purpose and content of messages and helps applications manage stored messages. MAPI also provides a common interface that application developers can use to create mail-enabled and mail-aware applications independent of the underlying messaging system.

MAPI includes functions and interfaces for messaging service client applications and messaging service providers. A subset of MAPI implements the Common Mail Calls (CMC) interface, developed by the XAPIA and supported by Microsoft for cross-platform messaging.

MAPI uses an object-oriented programming model that can be used in standard $\mathrm{C}$ or $\mathrm{C}+$ programs. MAPI does not define administrative interfaces, gateway interfaces, or other mechanisms for installing or managing an underlying messaging system.

LMITCO will prefer products that support X.400 and SMTP/MIME. Even though E-mail products based on proprietary technology can be accessed through E-mail gateways, this approach will be discouraged since it often results in a loss of functionality.

\section{Preferred Products}

Lotus' LMS will be implemented as both a backbone message transfer agent and provider of gateway services to internal LMITCO messaging systems. LMS will provide backbone protocol support for both 1992 X.400 and SMTP/MIME.

LMS will also be used to provide directory services and directory synchronization to internal LMITCO messaging systems. The LMS Names Directory will be implemented initially, and take over the Central Names Directory, eventually. Likewise, directory synchronization is currently done by the Central Names Directory, but will be migrated to LMS.

A major goal of the architecture is to provide a means to include users of the existing messaging systems into the architecture while providing a growth and migration path for users of the older, legacy messaging systems to newer, more capable client/server messaging systems.

\section{Supported Products}

This is the baseline technical architecture document. As tactical plans are developed to migrate to the preferred product, a summary of the strategy will appear in this section. 


\section{APPLICATION DEVELOPMENT TOOLS}

\section{Overview}

Application development tools include: the tools used to plan, develop, and maintain management information systems; the tools used to design and implement the data structures; the tools used to design and implement the user interface; and the configuration management tools. The choice of tools and methods can have a significant effect on initial development and ongoing maintenance costs. The general strategy in this area is to develop applications which exhibit portability, scalability, and interoperability and to use the highest level tools available to optimize the productivity of application system developers and to support corporate goals of data sharing. sections.

The products identified in each application section also apply to the subordinate application

\section{Enterprise Application}

Enterprise applications are applications that maintain information and/or processes that are used throughout the company.

Data access and security are primary considerations in the selection of enterprise application tools. Delivery to all supported desktop platforms (Intel-based, Macintosh, UNIX) is usually required. The enterprise computing environment (which may include the host tier) is the central storehouse of corporate data. Large-scale transaction processing is typically employed, with response time and data storage requirements. Manageability and reliability of the applications and the traceability to the business rules which govern them are critical. Applications typically have long lifetimes (several years or more). For all these reasons, it is critical to use tools that incorporate the enterprise business model for planning and analysis. There may be several high-level tools appropriate for using the enterprise model and actually implementing the application. The ability to deliver the application to multiple desktop platforms is an important consideration in selecting the tool set. A possible exception to using high-level tools is when a function is implemented that will be used so widely and frequently that operational speed is imperative. In such a case, implementation with a third generation or lower language may be necessary to achieve operational requirements. 


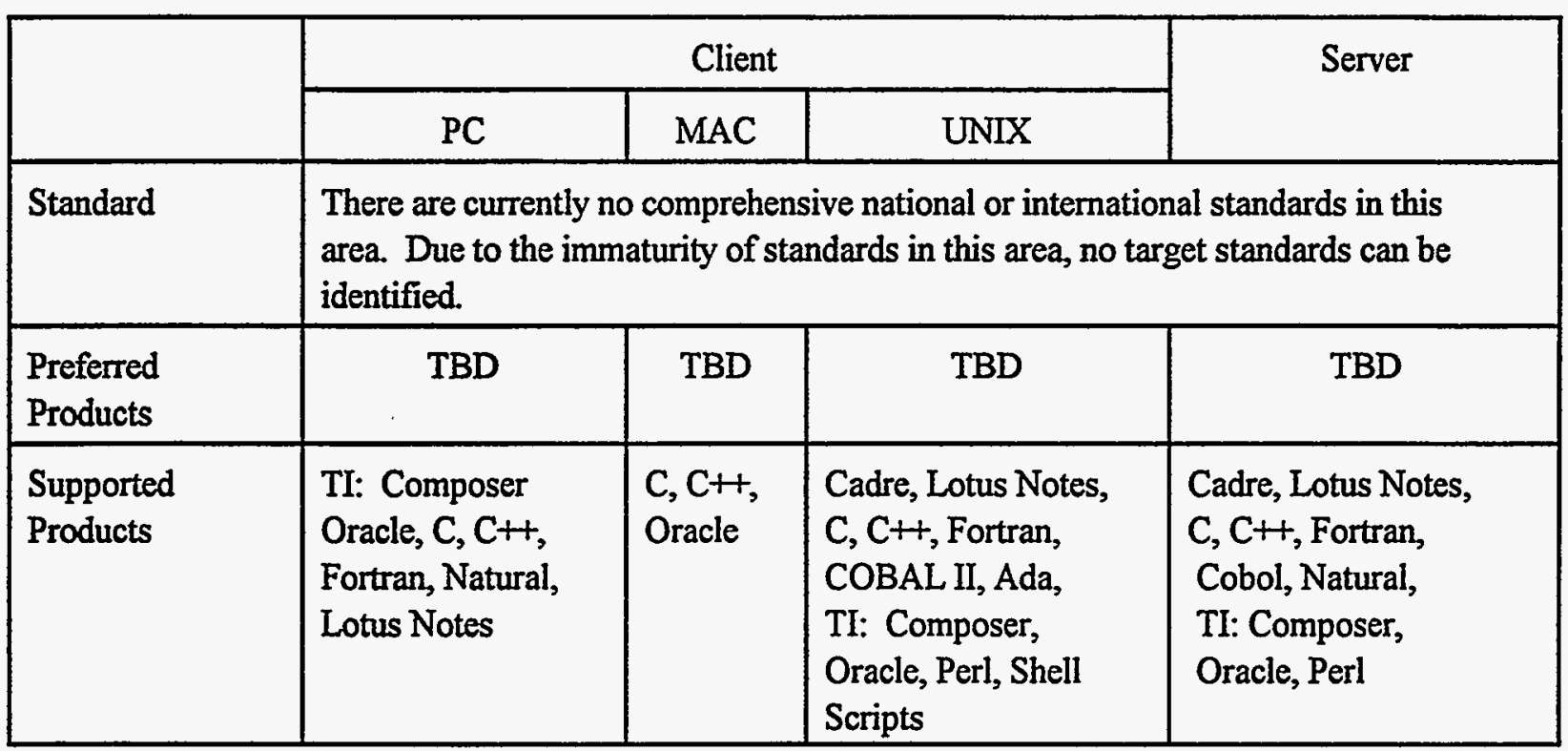

\section{Standard}

There are currently no comprehensive national or international standards in this area. Due to the immaturity of standards in this area, no target standards can be identified today. National Institute for Standards and Technology (NIST) developments in this area will be monitored.

Object-oriented approaches are of interest in this area. However, standards for object definition and management have not fully emerged. They will be addressed in future releases of the Technology Architecture as they evolve.

\section{Preferred Products (Candidates)}

Texas Instrument's (TI) Composer is an environment for the planning and analysis phases associated with the development of enterprise-wide applications. A central encyclopedia has been established to provide central management of the various business and system models built to support these systems. Oracle lacks an encyclopedia that provides the management of various business and system models. TI's Composer also has an environment for the design phase associated with the development of enterprise-wide applications.

TI's Composer and Oracle's Computer Assisted Software Engineering (CASE) are tools that can be used for the implementation phase associated with the development of enterprise-wide applications. The use of Third-Generation Language (3GL) in this area is discouraged, unless the $3 \mathrm{GL}$ code is generated by a code generation component, in which case $C$ should be used. Developers should utilize TI's Composer when it is desirable to package code to run in a server environment (as opposed to all code being located on the client, with remote access to the data).

TI's Composer developer's environment currently exists on the Inter-based client and the UNIXbased client. Composer will produce applications that will operate in the UNIX and Intel environments and will support both character-based (i.e., terminal emulation) and multiple graphical user interface 
(GUI) environments (e.g., Windows and MOTIF) interfaces. Currently, Composer does not plan to support the Macintosh platform for development or as a target platform.

The Oracle's CASE developer's environment currently exists on the Inter-based client, the UNIX client, the Macintosh client, and certain server platforms. Oracle will produce applications that will operate in the UNIX, Intel-based, Macintosh, and certain server environments. To target for the UNIX and Macintosh environments requires the UNIX and Macintosh developer's environments, respectively.

\section{Supported Products}

This is the baseline technical architecture document. As tactical plans are developed to migrate to the preferred product, a summary of the strategy will appear in this section.

\section{Workgroup Applications}

Workgroup applications are applications that maintain information and/or processes for specific programs or departments within the company. Workgroup applications are unique to a specific user group within those programs or departments.

\begin{tabular}{|c|c|c|c|c|}
\hline & \multicolumn{3}{|c|}{ Client } & \multirow[t]{2}{*}{ Server } \\
\hline & $\mathrm{PC}$ & MAC & UNIX & \\
\hline Standard & \multicolumn{4}{|c|}{$\begin{array}{l}\text { There are currently no comprehensive national or international standards in this } \\
\text { area. Due to the immaturity of standards in this area, no target standards can be } \\
\text { identified. }\end{array}$} \\
\hline $\begin{array}{l}\text { Preferred } \\
\text { Products }\end{array}$ & TBD & TBD & TBD & TBD \\
\hline $\begin{array}{l}\text { Supported } \\
\text { Products }\end{array}$ & $\begin{array}{l}\text { Visual Basic, } \\
\text { Oracle, } \\
\text { TI: Composer, } \\
\text { Lotus Notes }\end{array}$ & $\begin{array}{l}\mathrm{C}, \mathrm{CH}, \\
\text { Oracle, } \\
\text { Fortran }\end{array}$ & $\begin{array}{l}\text { Ada, Small } \\
\text { Talk, Oracle, } \\
\text { C, C++, } \\
\text { Fortran, Perl }\end{array}$ & $\begin{array}{l}\text { Oracle, TI: Composer, C, C+H, } \\
\text { Fortran, Ada, Perl }\end{array}$ \\
\hline
\end{tabular}

\section{Standard}

There are currently no comprehensive national or international standards in this area. Due to the immaturity of standards in this area, no target standards can be identified.

\section{Preferred Products (Candidates)}

Developers may utilize Oracle CASE when building departmental/workgroup applications that utilize data in Oracle databases and which are deploying to either character-based (i.e., terminal emulation), Windows, or MOTIF environments. The Oracle CASE developer's environment currently exists on the Intel-based client, the UNIX-based client, and on certain host tier environments. The Oracle 
CASE environment will produce applications that will operate in the UNIX and Intel-based client environments, or in certain server environments.

\section{Supported Products}

This is the baseline technical architecture document. As tactical plans are developed to migrate to the preferred product, a summary of the strategy will appear in this section.

\section{Stand Alone Applications}

\begin{tabular}{|l|l|l|l|l|}
\hline \multirow{2}{*}{} & \multicolumn{3}{|c|}{ Client } & \multirow{2}{*}{ Server } \\
\cline { 2 - 5 } & \multicolumn{1}{|c|}{ PC } & MAC & UNIX & \\
\hline Standard & \multicolumn{2}{|c|}{$\begin{array}{l}\text { There are currently no comprehensive national or international standards in this area. } \\
\text { Due to the immaturity of standards in this area, no target standards can be identified. }\end{array}$} \\
\hline $\begin{array}{l}\text { Preferred } \\
\text { Products }\end{array}$ & TBD & TBD & TBD & TBD \\
\hline $\begin{array}{l}\text { Supported } \\
\text { Products }\end{array}$ & $\begin{array}{l}\text { TI: Composer, } \\
\text { Oracle, FoxPro, } \\
\text { MS Access, } \\
\text { MS Visual Basic, } \\
\text { C, C++, dBase }\end{array}$ & $\begin{array}{l}\text { FoxPro, } \\
\text { Oracle }\end{array}$ & $\begin{array}{l}\text { Oracle, C, } \\
\text { C++, } \\
\text { Fortran, } \\
\text { Ada, Perl, } \\
\text { Lisp, sh, } \\
\text { csh }\end{array}$ & $\begin{array}{l}\text { Oracle, C, C++, Fortran-77, } \\
\text { Ada, Fortran-90 }\end{array}$ \\
\hline
\end{tabular}

\section{Standard}

There are currently no comprehensive national or international standards in this area. Due to the immaturity of standards in this area, no target standards can be identified.

\section{Preferred Products}

TBD

\section{Supported Products}

This is the baseline technical architecture document. As tactical plans are developed to migrate to the preferred product, a summary of the strategy will appear in this section.

\subsection{Configuration Management Tools}

In a distributed computing architecture, configuration management is not a trivial consideration. Automated support in the form of configuration management tools will be required to maintain such an environment. 


\begin{tabular}{|c|c|c|c|c|}
\hline & \multicolumn{3}{|c|}{ Client } & \multirow[t]{2}{*}{ Server } \\
\hline & PC & MAC & UNIX & \\
\hline Standard & \multicolumn{4}{|c|}{$\begin{array}{l}\text { There are currently no comprehensive national or international standards in this } \\
\text { area. Due to the immaturity of standards in this area, no target standards can be } \\
\text { identified. }\end{array}$} \\
\hline $\begin{array}{l}\text { Preferred } \\
\text { Products }\end{array}$ & \multicolumn{4}{|c|}{$\begin{array}{l}\text { Without further experience, it is not possible to establish which additional tools } \\
\text { should be considered preferred products. }\end{array}$} \\
\hline $\begin{array}{l}\text { Supported } \\
\text { Products }\end{array}$ & none & none & $\begin{array}{l}\text { SCCS, RCS, } \\
\text { Continuous SCM }\end{array}$ & Librarian CCF, RCS, SCCS \\
\hline
\end{tabular}

\section{Standards}

There are currently no comprehensive national or international standards in this area, therefore, no standards can be identified today. In the absence of such standards, the preferred strategy will be to identify a small set of products that meets most of the needs of the application development community and focus procurement and support upon these tools.

\section{Preferred Products}

Without additional experience, it is not possible to establish which of the products currently used in LMITCO should be considered preferred products. Because of the impact on the development environment and plans for the professional staff, it is important that the preferred products be established as early as possible.

\section{Supported Products}

Tools in use in software projects today include RCS (Revision Control System) and Source Code Control System (SCCS) for UNIX systems, Librarian and Change Control Facility (CCF) for multiple virtual systems (MVS) platforms, WorkCenter for NT, and Code Management System (CMS) for VM platforms.

\subsection{User Interface}

Human/computer interaction define how people can interact with computer-based applications. Depending on the capabilities required by the user and on the application, such an interface may include the presentation of an application to the user, distribution of the display of an application across the network, and window management.

The human usually interacts with the computer through a display, a keyboard, and possibly a pointing device such as a mouse, a joystick, or a touch screen. Character display allows for only character-level resolution on the screen. However, today most screens are able to display information using individual pixels, enabling a much finer resolution. The application can then use real-world metaphors, such as push buttons and check boxes, and multiple windows and dialogs to build a Graphical 
User Interface (GUT). With consistent and realistic metaphors, the user can interact with an application more easily and with less training.

There are three basic interfaces: user, program, and machine. The user interface is the human interface to the computer dealing with how information is presented and how information is requested. The program interface is how programs communicate with each other to accomplish a task behind the scenes. The third interface is machine to machine such as in a data acquisition process.

\section{Standard}

All applications should have a GUI consistent with the operating system on the target platform.

The preferred interface presentation method for networked applications is to use current Internet protocols [now Standard Generalized Markup Language (SGNFL) and HyperText Markup Language (HTML)]. These protocols provide a common interface that is platform and operating system independent.

\section{Preferred Products}

TBD

\section{Supported Products}

The supported interface presentation method for standalone applications is hardware and operating system dependent. Intel-based applications should have an MS Windows based user interface.

Purchased applications that do not support the Internet presentation style should use the GUI style supported by the operating system on the target platform. Purchased networked applications should avoid hardware and operating system dependencies and vendor specific protocols. 


\section{OPERATING SYSTEMS}

\section{Overview}

Operating systems provide the core services needed to execute and administer application systems running on computing platforms. These systems also provide an interface between applications software and computing platforms. Operating system services include the subcomponent functions of kernel operations, system administration commands and utilities, and system management. For the purposes of the TA, "operating systems" also include the myriad of products that are run along with the basic "operating system" to provide expanded services. Examples are Access Control Facility 2 (ACF2), Virtual Storage Access Method (VSAM), CA-1, and many, many others.

\begin{tabular}{|c|c|c|c|c|}
\hline & \multicolumn{3}{|c|}{ Client } & Server \\
\hline Standard & \multicolumn{4}{|c|}{ TBD } \\
\hline \multirow{2}{*}{$\begin{array}{l}\text { Preferred } \\
\text { Products }\end{array}$} & $\mathrm{PC}$ & MAC & UNIX & \multirow[t]{2}{*}{ TBD } \\
\hline & Windows & $\mathrm{Mac} / \mathrm{OS}$ & System V & \\
\hline $\begin{array}{l}\text { Supported } \\
\text { Products }\end{array}$ & $\begin{array}{l}\text { MS DOS } \\
\text { Windows } \\
\text { Win NT }\end{array}$ & Mac/OS & \multicolumn{2}{|c|}{$\begin{array}{l}\text { Sun Solaris, DEC Ultrix, HP HP-UX, SGI IRIX, } \\
\text { IBM AIX, Sun OS, Netware, CICS, VM/ESA, } \\
\text { MVS/ESA, CICS/ESA, Windows NT Server }\end{array}$} \\
\hline
\end{tabular}

\section{Standard}

Federal Information Processing Standard Publication (FIPS PUB) 151-2 defined Portable Operating System Interface for UNIX (POSIX) interface standards. This important interface standard was based on a family of IEEE standards that describes such entities as operating systems, languages, and security.

POSIX is not an operating system, nor is it UNIX. Rather, POSIX provides a set of standards against which operating systems from different vendors may be measured to verify that they are "POSIX compliant." The measure of POSIX compliance or adaptation by vendors will determine the "degree of openness" of their systems environments. Recently, the acceptance of Spec 1170 by the X/Open Corporation Limited has replaced POSIX as the standard set of API. X/Open is where much of the work that is done by the multitude of organizations that develop Open standards (IEEE, OSF, ANSI, etc.) is integrated for a total Open Systems environment, which adds value for the customer who chooses to deploy Open Systems.

\section{Preferred Products}

The popularity of Microsoft NT is being evaluated for future use. Primary considerations include: enterprise scalability, administrative efficiency, security, X.500 compatibility, auditability, throughput, and the ablilty to seemlessly interact with other operating system environments on the $\mathbb{N E L}$ Information Network (INEL INET). 
LMTCO will continue to monitor the operating system products available on the market, including present and future versions of Windows 95 and Windows NT, and the various implementations of the UNIX operating system.

\section{Supported Products}

MS DOS versions V6.x and MS Windows after v3.11 are supported across LMITCO. Various vendor versions of UNIX, such as Digital UNIX, Sun Solaris, HP-UX, IBM AIX, DEC ULTRIX, Sun OS, and SGI IRIX, are found on desktops and servers and are supported.

NetWare 3. $x$ and 4. $x$ are currently supported. The existing distribution of servers is roughly 2 to 1 in favor of NetWare 3.x, roughly 85 of the approximately 130 existing servers have yet to be upgraded. Advanced features in NetWare 4.x such as X.500 spec 93 based directory services and a distributed database of all network resources distinguish NetWare 4.x as the best choice for file, print, and gateway services at this time. Central Processing Unit (CPU) intensive applications such as real time data acquisition systems or other such vertical market applications may find Microsoft NT a better choice.

The use of Virtual Machine/Enterprise System Architecture (VM/ESA) evolved as a defacto standard for the OS supporting Electronic Mail System at LMITCO and for the majority of the systems across the nation on the IBM 9672-R31 Computer System. The VM/ESA system is the "open edition" version of VM and is POSIX compliant. This version is in conformance with Federal Information Processing Standard (FIPS) 151-2, providing an open system foundation for future growth.

The use of Multiple Virtual Systems (MVS/ESA) evolved as a defacto standard for business computing across the country and at LMITCO. There is no other OS that will run the legacy applications that are currently running on the IBM 3090-300J computer system. The MVS/ESA open edition versions of MVS is estimated to be about $95 \%$ POSIX compliant. MVS/ESA V5.2X is expected to be the first OS to be branded as an open system by the X/open corporation limited.

The use of Customer Information Control System (CICS) at LMITCO and nationwide as a standard is due to the application systems that require the CICS support software. CICS VI.7 is not supported by the vendor, but is required for LMITCO Automated Document Control (ADOC) System and is supported by the Mainframe System Support Unit to the extent that it continues to run. CICS/ESA V3.3 is supported. The CICS/ESA V4.1 "open edition" software is to support the FIPS 151-2 standard and to become POSIX compliant. 


\section{DESKTOP PRODUCTIVITY SOFTWARE}

\section{Overview}

It is at the desktop that many of the components of the technical architecture are assembled, providing access to personal, departmental, and enterprise computing. Because of the number of desktop computers and their role in present and future computing, it is necessary to promote advancement of distributed computing and optimization of financial resources.

Historically, the primary purpose of desktop computing has been to provide end users with application tools to assist them with accomplishing their jobs. Initially, inconsistency between the configuration of various user's machines posed only minor problems because these machines were used for personal computing. Before long, business practices were based on using certain software packages that required a level of consistency necessary for users to be able to exchange files. Then the introduction of networking, file sharing, and distributed processing required a higher level of consistency for both minimum hardware and applications. The preferred end-user desktop configuration includes a set of applications that provides access to personal, departmental, enterprise, and Internet data through an interface compatible to the user's platform, middleware, and support libraries for each hardware platform.

\begin{tabular}{|l|l|l|c|}
\hline & \multicolumn{1}{|c|}{ PC } & \multicolumn{1}{c|}{ MAC } & UNIX \\
\hline Standard & \multicolumn{3}{|c|}{ There are currently no standards in this area. } \\
\hline $\begin{array}{l}\text { Preferred } \\
\text { Products }\end{array}$ & $\begin{array}{l}\text { MS Office Standard } \\
\text { MS Office Professional }\end{array}$ & $\begin{array}{l}\text { MS Office Standard } \\
\text { MS Office Professional }\end{array}$ & None \\
\hline $\begin{array}{l}\text { Supported } \\
\text { Products }\end{array}$ & $\begin{array}{l}\text { MS Office Standard } \\
\text { MS Office Professional } \\
\text { WordPerfect }\end{array}$ & $\begin{array}{l}\text { MS Office Standard } \\
\text { MS Office Professional }\end{array}$ & None \\
\hline
\end{tabular}

\section{Standard}

Currently no standards exist in this area.

\section{Preferred Products}

Only three suites were determined to be candidates for use at LMITCO: Perfect Office (Novell), Microsoft Office (Microsoft), and Smart Suite (Lotus). Each of these products was evaluated independently against a benchmark set of minimum functional requirements and desired performance features. The products selected that best met LMITCO's needs was Microsoft Office Standard and Microsoft Office Professional. The Standard product includes the following applications: Word (word processor), Excel (spreadsheet), and PowerPoint (presentation graphics). The Professional product adds the Access application to the above three for end-user database needs. 


\section{Supported Products}

The FoxPro database tool was also recommended by the working group for stand alone level database development and will continue to be supported in addition to Access. Other products replaced by the selection of MS Office functionally will continue to be supported for a limited time in accordance with plans for full implementation. Such announcements will be made periodically. 


\section{DATA INTERCHANGE}

\section{Overview}

To facilitate communications, data must be moved among organizations, across platforms and systems, and among applications and information products; data must also be available as human readable output from those applications. Components of this category include text data, spreadsheet data interchange, desktop publishing interchange, graphics interchange, image compression/decompression, and calendar data. Other types could include geospatial or geographical data and specialized or scientific data.

\begin{tabular}{|c|c|c|}
\hline & Client & Server \\
\hline Standard & \multicolumn{2}{|c|}{ SGML, Adobe's PDF* } \\
\hline $\begin{array}{l}\text { Preferred } \\
\text { Products }\end{array}$ & \multicolumn{2}{|c|}{ TBD } \\
\hline $\begin{array}{l}\text { Supported } \\
\text { Products }\end{array}$ & \multicolumn{2}{|c|}{ TBD } \\
\hline
\end{tabular}

\section{Standard}

There is a DOE initiative to have all contractors begin implementing SGML for their external scientific and technical documents by 1998. LMITCO is in the process of implementing a procedure that will convert external documents to SGML format. In the future it is intended that SGML will be used to format all information including: spreadsheet data, desktop publishing, graphics, image compression/decompression and calendar data.

*In the interim, the Office of Science and Technical Information (OSTI) has identified Adobe's Portable Document Format (PDF) as an acceptable standard for scientific and technical documents.

\section{Preferred Products}

TBD

\section{Supported Products}

TBD 


\section{DATA MANAGEMENT}

\section{Overview}

Structured management of data is central to information technology. Data management technologies and products permit data to be defined independently of the processes that create and use it, to be maintained indefinitely, and to be shared among many processes. Data management services include management systems, services and data dictionaries, and repositories.

Data Base Management Systems (DBMS) provide facilities that manage the storage, modification, and access to structured data. DBMS provide concurrent control procedures and mechanisms to combine data from different databases. DBMS services are accessible through programming language interfaces or fourth-generation language interfaces. DBMS generally provide specific services to define, create, populate, maintain, query, backup, restore, archive, recover, and protect the integrity of databases. This section will consider three general categories of DBMS: relational, full-text, and object-oriented.

Data Management: Database Management

\begin{tabular}{|l|l|l|l|l|}
\hline & \multicolumn{3}{|c|}{ Client } & \multirow{2}{*}{ Server } \\
\hline & \multicolumn{1}{|c|}{ PC } & MAC & UNIX & \multicolumn{3}{|c|}{ ANSI/ISO SQL } \\
\hline Standard & \multicolumn{4}{|c|}{$\begin{array}{l}\text { Oracle, DB2 V4 for MVS, } \\
\text { ADABAS-D V2 }\end{array}$} \\
\hline $\begin{array}{l}\text { Preferred } \\
\text { Products }\end{array}$ & $\begin{array}{l}\text { MS Access, } \\
\text { Oracle }\end{array}$ & Oracle & Oracle \\
\hline $\begin{array}{l}\text { Supported } \\
\text { Products }\end{array}$ & $\begin{array}{l}\text { MS Access, } \\
\text { Oracle, FoxPro, } \\
\text { Lotus Notes }\end{array}$ & Oracle & $\begin{array}{l}\text { Informix, } \\
\text { Ingres, } \\
\text { Sybase, } \\
\text { Oracle }\end{array}$ & $\begin{array}{l}\text { Oracle, DB2 V4 for MVS, } \\
\text { ADABAS-D V2, } \\
\text { ADABAS-CV5.3.3 }\end{array}$ \\
\hline
\end{tabular}

\section{Standard}

Relational DBMS are used for most general-purpose database applications that process traditional types of data such as structured character, numeric, and date data types. More than $90 \%$ of the new DBMS licenses being acquired worldwide today are for relational DBMS products. Relational DBMS products within LMITCO must adhere to one of two target database standards. For middle-and high-end servers and all hosts, relational DBMS should conform to Database Language Structured Query Language (SQL) as specified by ANSI X3.135-1992 and International Standards Organization/International Elecrotechnical Commission (ISO/IEC) 9075-1992 standards. For desktop and low-end servers, relational DBMS should conform to the industry de facto Xbase language definition. It is also an option for relational DBMS for desktop and low-end servers to conform to ANSI/ISO Database Language SQL. SQL was adopted by NIST in FIPS PUB 127-2 as the Federal Government standard database language and architecture for relational DBMS. Data Manipulation Language (DML), Data Definition Language (DDL), and specifications for security facilities are defined in the SQL standard. The Xbase language 
was first made popular by Ashton-Tate in dbase (dbase is now a product of Borland International). In late 1992 a new ANSI technical committee X3J19 was formed to produce an ANSI standard for Xbase, and that work is now under way.

Full-text DBMS are specialized in their ability to store and manipulate textual data and documents of varying lengths and complexity. Full-text DBMS, that are sometimes referred to as text information management systems, provide specialized capabilities for indexing and searching text data strings, including features for keyword retrievals, proximity searching, thesaurus, and string editing. There are no complete formal standards (ANSI, ISO, IEEE, etc.) for full-text DBMS, although there are some relevant standards that merit consideration. The Information Retrieval Protocol, ANSI Z39.50-1988, specifies protocols for text retrieval. Also, the ANSI X3H2 Database Committee is developing SQL for defining syntax and semantics for SQL extensions to address handling of multimedia data, including large text fields. Another standardization activity applicable to the storage and retrieval of full-text data is SGML. ANSI SQL and SGML offer the greatest potential and are our target standards for full-text DBMS.

Object-oriented DBMS are designed to store and manage complex types of data, along with associated methods (rules and process logic for the data). Object-oriented DBMS can manage very large bitmapped data types, store complex types of data (lines, images, voice, etc.), and, in many cases, integrate these DBMS capabilities with object-oriented programming languages such as $\mathrm{C}++$, Smalltalk, and LISP. There are no formal standards (ANSI, ISO, IEEE, etc.) for object-oriented DBMS, although there are some relevant standardization activities in the field. One object-oriented DBMS specification is the Object Database Management Group (ODMG)-93 Object Database Standard. ODMG-93 is a specification for OQL that is detailed in a commercially published book written by individual experts who represent some of the object-oriented database vendors participating as members in the ODMG consortium. There are also two related object-oriented DBMS standardization projects well under way within ANSI: the X3H2 Database Committee is developing an extension of SQL (commonly referred to as SQL3) that will add numerous object-oriented constructs to the next version of the SQL standard, and the X3H7 OIM Committee is defining an object-on-oriented data model standard. $\mathrm{X} 3 \mathrm{H} 2$ and $\mathrm{X} 3 \mathrm{H} 7$ are working together closely, and ODMG has recently stated their intention to work toward full conformance to ANSI SQL and the Object Information Management (OIM) data model.

In summary, the continuing LMITCO DBMS strategy is to propose and support leading DBMS products that provide the required technical functionality to meet our needs, while conforming to formal published standards where possible, for each DBMS category and platform of the computing architecture.

\section{Preferred Products}

Desktops. There are two general categories of DBMS used on desktops: Desktop clients accessing server DBMS applications and a stand alone desktop DBMS applications. The preferred DBMS products for desktop clients depend upon specific applications and/or user processes since numerous codes (either commercial products or codes developed in-house) can typically access server databases. The preferred DBMS product for stand alone desktop DBMS applications is FoxPro for both PC and Macintosh PCs; Oracle is the preferred product for UNIX platforms. There are no preferred full-text or object-oriented DBMS products for the desktop at present. 
Servers. The preferred relational DBMS product for servers is Oracle for UNIX and Virtual Memory System (VMS) platforms and DB2 for the MVS platform. There is no preferred full-text DBMS product for servers at present because of the absence of comprehensive adopted standards. There is no preferred object-oriented DBMS product at present.

The Database 2 (DB2) Version 2 Release 3 DBMS is a high-end relational DBMS supporting SQL access to stored data. It provides full functional services and utility components allowing for referential constraint enforcement. It supports data sharing across hardware platforms in a client/server distributed environment.

\section{DB2 Version 4}

- Supports large distributed network client/server applications

- $\quad$ Provides for major scalability and parallelism (thru parallel=CPU and parallel-DB2 subsystem processing)

- Improves data sharing by reduced index locking and row-level locking

- Concurrency elevates from 10,000 to 25,000 maximum connected distributed users per DB2 subsystem with 2,000 simultaneously active threads

- Provides for stored procedures and SQL outer join capability.

ADABAS SQL SERVER is fully compliant SQL interface to ADABAS C and delivers SQL functionality to the most highly rated, reliable high-performance DBMS available on high-end systems today.

ADABAS D, an extremely robust implementation of a SQL compliant relational data model, is well suited for business-critical applications.

\section{Supported Products}

Currently, DB2 Version 2 Release 3 is the only supported relational DBMS supported on the IBM 3090-300J computer system.

The chosen DBMS for LMTTCO's Business Management Systems is ADABAS C V5.3.3, a high performance multi-threaded database management system that offers complete interoperability, scalability, and portability across desktop, LAN, UNIX, mid-range, and mainframe environments. With ADABAS $\mathrm{C}$ a single application can access data distributed across multiple heterogeneous platforms.

Current released versions of ADABAS C/D and ADABAS SQL SERVER are available on almost all mainframes and non-mainframe platforms (including OS/2, UNIX, and Windows NT). 
RDA is used to establish a remote connection between an RDA client, acting on behalf of an application program or user process, and an RDA server, interfacing to a process that controls service requests to and from a database. The goal is to promote the interconnection and interoperability of database applications across heterogeneous environments for SQL server databases. RDA provides location transparency of databases; that is, all databases accessed by an application program or user process appear to be located centrally although they may be located across multiple servers and/or hosts.

\begin{tabular}{|l|c|c|c|c|}
\hline & \multicolumn{3}{|c|}{ Client } & \multirow{2}{*}{ Server } \\
\hline & PC & MAC & UNIX & ANSI/SO RDA \\
\hline Standard & \multicolumn{4}{|c|}{ TBD } \\
\hline $\begin{array}{l}\text { Preferred } \\
\text { Products }\end{array}$ & \multicolumn{4}{|c|}{ TBD } \\
\hline $\begin{array}{l}\text { Supported } \\
\text { Products }\end{array}$ & TBD & TBD & TBD & TBD \\
\hline
\end{tabular}

\section{Standards}

RDA is fully developed and specified for relational DBMS because of the existence of and support for the standard for Database Language SQL for relational DBMS. RDA for full-text and objectoriented DBMS will depend largely on development of additional standards.

Relational DBMS products that provide for RDA should comply with the RDA standard being specified by the ANSI $\mathrm{X} 3 \mathrm{H} 2$ and ISO database language committees. This standard sets forth the calling protocol for remote database service requests. Although this standard has not been finalized and formally adopted by ANSI, there have been public reviews of the draft standard both within the United States and internationally. These public reviews have produced an RDA working draft standard that is stable, and relational database vendors have begun to develop and market RDA products that conform to this draft standard. The draft RDA standard consists of two parts: (1) Generic Model, Service, add Protocol and (2) SQL Specialization.

Other activities relating to RDA include SQL Access Group (SAG), an industry consortium of leading database vendors that has adopted the SQL standard (ANSI X3.13 5-1992) and the working draft ANSI/ISO RDA specifications and built demonstration applications to show remote database interoperability between their various DBMS products on various computing hardware and operating system platforms. While not an actual or proposed standards group, SAG is important because of the marketplace and industry awareness and promotion of ANSI/ISO SQL and RDA standards that it has created.

Recently, Open Database Connectivity (ODBC) from Microsoft has also emerged as a viable technology for relational database applications interoperability and RDA. ODBC features an SQL-based 
data access service and concurrent access to multiple DBMS. Various vendors are working to offer relational DBMS products that conform to ODBC, although there is no official test suite to verify ODBC compliance. ODBC is a specification owned by Microsoft; it is not governed by any formal standardization body (ANSI, ISO, IEEE, etc.).

\section{Preferred Products}

Because there are no formal, approved standards for RDA, no specific product can claim to be "standards conforming" at present. LMITCO is currently using various products that provide RDA. These products and technologies include the communications and gateway products that correspond with the various relational DBMS products used in the company. For Oracle environments, SQL*Net is used for RDA between client applications and servers. Other products in use are NetLib and Omni*SQL from Sybase, which provide applications with RDA and interoperability across various DBMS environments including Sybase, Oracle, Rdb, and DB2.

Of the above product mix, Oracle SQL*Net is the single product that is preferred for RDA across all desktop and server platforms. Oracle SQL*Net provides RDA capabilities to Oracle, DB2, and other database sources. Oracle SQL*Net also provides more secure handling of access controls between clients and servers/hosts. All RDA transactions require a common network protocol on servers and clients, and the preferred network protocol for RDA is TCP/IP.

\section{Data Management: Data Dictionaries and Repositories}

Data dictionary services allow users with appropriate access privileges to access and modify metadata about the information stored in a database, network, or databases. Data attributes maintained by data dictionary services may include data names, data definitions, internal and external formats, integrity and security rules, and information about where the data element is used within the information architecture of the business. DBMS products use functional data dictionaries or catalogs internally to maintain their metadata.

\begin{tabular}{|c|c|c|c|c|}
\hline & \multicolumn{3}{|c|}{ Client } & \multirow[t]{2}{*}{ Server } \\
\hline & PC & MAC & UNIX & \\
\hline Standard & \multicolumn{4}{|c|}{$\begin{array}{c}\text { ISO IRDS2, ANSI/ISO } \\
\text { PCTE }\end{array}$} \\
\hline $\begin{array}{l}\text { Preferred } \\
\text { Products }\end{array}$ & \multicolumn{4}{|c|}{ IEF } \\
\hline $\begin{array}{l}\text { Supported } \\
\text { Products }\end{array}$ & IEF & TBD & TBD & IEF \\
\hline
\end{tabular}

\section{Standard}

Multiple industry and government expert participants have teamed with ANSI to define a data dictionary standard, Information Resource Directory System (IRDS). IRDS was published in 1988 as 
ANSI X3.138-1988, and this standard was subsequently adopted by NIST in FIPS PUB 156. The IRDS standard represented a significant first step toward compatibility among data dictionary implementations, and some dictionary vendors stated their intent to comply with the ANSI IRDS standard.

The 1988 IRDS standard was developed before the rapid advancement of CASE technology in recent years. It was developed primarily as a documentation and data administration tool, and its data model is more limited than the data modeling requirements of Integrated Computer Assisted Software Engineering (ICASE) technology. Major dictionary vendors and ICASE vendors have announced statements of direction and are pursuing rapid movement into support for distributed environments. The 1988 IRDS is currently being upgraded via the IRDS2 ISO project to include CASE support, while the ANSI X3H4 data dictionary standards committee has decided to abandon further IRDS development and work with ISO to develop a new, portable CASE tools environment standard for data dictionary/repository facilities. These development activities will create better data dictionary standards, but there is not yet a comprehensive formal standard for data dictionaries or repositories.

\section{Preferred Products}

LMITCO has focused practical data dictionary efforts on the functionally richer repository concept supported by the procurement and implementation of Texas Instruments' Information Engineering Facility (IEF) Encyclopedia. The IEF Encyclopedia is implemented on the MVS mainframe platform and is the preferred dictionary/repository product for desktops, servers, and hosts. IEF is also the company's preferred and supported CASE environment tool. The IEF Encyclopedia provides an active data dictionary for data modeling across desktops, servers, and hosts. IEF provides a data integration capability for the IEF ICASE tool products, providing support for an expanded base of objects and automated life-cycle activities. The IEF Implementation Toolset is an optional product with in IEF that will generate applications code that can be executed across all tiers of the computing architecture. 


\section{INTERNET ACCESS}

\section{Overview}

Internet access refers to those applications through which corporate information may be formally published and accessed by users of distributed computer systems. These services are distinguished from informal communication systems such as electronic mail by a controlled information source through which access is granted to authorized users. In contrast, electronic mail allows users to send information to other users at their own discretion.

Internet access is an emerging and rapidly changing area of technology. Over the past 2-1/2 years, a phenomenal growth in network information services has been witnessed on the Internet, first in the rapid deployment of the University of Minnesota's Gopher technology and then by the explosion of the World Wide Web. The Web technology originated at the European Laboratory for Particle Physics (CERN) in Geneva, Switzerland, but was popularized when the National Center for Supercomputing Applications (NCSA) at the University of Illinois began distributing its Mosaic Web client (or "browser") for UNIX, Windows, and Macintosh platforms.

\section{Network Information}

\begin{tabular}{|l|c|c|}
\hline & Client & Server \\
\hline Standard & \multicolumn{2}{|c|}{ HTTP/HTML } \\
\hline $\begin{array}{l}\text { Preferred } \\
\text { Products }\end{array}$ & Netscape Navigator & NCSA httpd \\
\hline $\begin{array}{l}\text { Supported } \\
\text { Products }\end{array}$ & Netscape Navigator, NCSA Mosaic & $\begin{array}{c}\text { NCSA httpd, CERN httpd, } \\
\text { Netscape Commerce }\end{array}$ \\
\hline
\end{tabular}

\section{Standard}

Although official standards in the area of network information servers are in the early stages of development, the de facto standards used on the World Wide Web appear to be the basis for future standards development in this area. HyperText Transport Protocol (HTTP) is the protocol used to transfer documents from a Web server to a Web client.

Within LMITCO the most pervasive HTTP server software is the freeware NCSA httpd. There are organizations which are beginning to use commercially available server software; most notably Netscape Commerce Server that provides some security extensions (like encryption) not available in the freeware servers.

Wide Area Information Servers (WAIS) is the protocol used most often on the Web for information search and retrieval applications. Other specialized information search and retrieval products, e.g., the BasisPlus software on which the company's library catalog system is based, may be interfaced with the Web in a manner that is transparent to users. Within the DOE complex a software 
package known as HARVEST is gaining momentum as the preferred indexing/retrieval engine in addition to the freeware WAIS engine.

The World Wide Web provides the most versatile system for accessing information. A Web client can directly access a number of services, including Netnews, Gopher, and Anonymous FTP; it can also display numerous document formats using external applications. In addition, the Web architecture allows almost any type of service to be accessed transparently through a server-based common gateway interface (CGI).

The primary document format used on the Web is HyperText Markup Language (HTML), a subset of SGML. SGML is an ANSI-standard format and is the DOE standard for document interchange. In applications where the information must be delivered in more than one format, it may be more efficient to maintain the original document source in SGML and produce the required output formats, including HTML, from that one source.

The current published and approved HTML standard is version 2. Version 3 is being drafted. Functionality increases as the version number goes up. Forms began to appear in browsers as the version 2 standard was being developed (version 2 defined the forms interface). Version 3 defines tables and additional functionality such as background colors and transparent graphics backgrounds. Version 3 extensions are currently available in the company standard Netscape Browser. The adoption of these extensions before the formal adoption of the HTML standard tends to make the HTML browser specific.

SGML viewers that can be incorporated into the standard LMITCO browser are also freely available. This shows the movement in the direction of SGMLs adoption as a document standard format.

One of the emerging technologies (which is being demonstrated and used at LMITCO as well as the rest of the World Wide Web (WWW) community) is the marrying of HTML forms and relational databases. The WOW freeware from Oracle Corp. (the LMITCO RDBMS standard) allows the accessing of Oracle databases through HTML forms. The freeware Gateway SQL (GSQL) interface (available from NCSA) supports the same kind of HTML access to Sybase-based databases (as well as providing a template for the development of interfaces to other RDBMSs). Both of these software packages are based on the WWW CGI (common gateway interface) that allows the httpd software (and browser clients) access to non-www based software systems through HTML-' based user interfaces (i.e., forms). This CGI seems to be the wave of the future for client/server application development. This approach also serves as a mechanism to integrate legacy systems into the www based enterprise computing environment.

Virtual Reality Modeling Language (VRML) technology (providing a 3d representation) is also becoming widely popular. There are several freeware browsers that provide access to these types of information stores.

Another important related technology is the WAIS system that is an implementation of ANSI Standard Z39.50, Information Retrieval Protocol. WAIS appears to be emerging as the preferred freeware index and retrieval engine for the World Wide Web.

SUN's HotJava browser and development language (Java) are also being widely touted as the wave of the future. This technology allows not only for the viewing of HTML based information but 
integrates the downloading and execution of program units known as applets. These applets can be any software application and need not reside on the client machines. The applets are downloaded as needed much as HTML pages are now.

\section{Preferred Products}

Lockheed Martin Corporation has obtained a corporate wide license for the Netscape Navigator Web Browser; this product is available through the corporation at no cost to LMITCO, with versions for most of the popular computing platforms. Netscape Navigator is LMITCO's standard web browser. LMITCO will support the Netscape Navigator Web Browser, under the Lockheed Martin Corporate License.

\section{Supported Products}

This is the Baseline Technical Architecture Document. As tactical plans are developed to migrate to the preferred product, a summary of the strategy will appear in this section. 


\section{SECURITY}

\section{Overview}

The principle objectives of this service area are to provide confidentiality, integrity, and availability of the company's information resources. Confidentiality is the protection of information from unauthorized access viewing; integrity is the protection of information from intentional or accidental unauthorized changes; and availability is the assurance that information is accessible by authorized users when needed. These objectives are achieved through a combination of administrative rules and procedures augmented or implemented through various technical means. The legacy situation within LMITCO has been to rely primarily on administrative security measures. The target environment will be to utilize evolving technology such as Open Systems Foundation Distributed Computing Environment (OSF/DCE) security services and Rivest Shamir Adelman (RSA) public key encryption, where possible, as a means for implementing required security attributes. The technical architecture specification primarily addresses the technical tools used as a part of an overall security strategy.

The security level that will be enforced at LMITCO has not been determined yet. The DOD 5200.28-STD, C2 and B2 issues that apply to LMITCO will be a part of that implementation plan to be determined.

\section{Security Technology and Tools}

Each of the technologies described below provides for one or more of the required information security objectives; confidentiality, integrity, and availability.

\begin{tabular}{|l|c|c|}
\hline & Client & Server \\
\hline Standard & & TBD \\
\hline $\begin{array}{l}\text { Preferred } \\
\text { Products }\end{array}$ & & TBD \\
\hline $\begin{array}{l}\text { Supported } \\
\text { Products }\end{array}$ & $\begin{array}{c}\text { FPROT, } \\
\text { DISINFETANT, S/Key, } \\
\text { WIPEINFO, NTFS }\end{array}$ & $\begin{array}{c}\text { ACF2 + Natural Security for IBM } \\
\text { MPX3000, Security 3000 and VEAUDIT } \\
\text { for HP3000, S/Key, WIPEINFO, NTFS }\end{array}$ \\
\hline
\end{tabular}

\section{Standard}

While there are many tools and technologies that currently exist in various levels of development, the OSF DCE appears to offer the most promising package of integrated security services. It appears to have the support of many of the major vendors such as Digital Equipment Corporation (DEC), IBM, and Hewlett-Packard (HP). As proposed, it will offer authentication and authorization, data integrity, and data protection capabilities that are flexible enough to meet the requirements of both unclassified and classified computing environments. These capabilities are not "layered" on the operating system but are integrated within it and provide for centralized administration. DCE is an evolving technology that is not mature at this time. For example, DCE technology has not yet made a significant appearance in the client world at this time. However, it is not proprietary technology and so has the flexibility to adapt to the 
changing market. At the current time it is the most viable candidate for providing the type of integrated security services that will be needed in future computing environments.

\section{Preferred Products}

TBD

\section{Supported Products}

The current environment utilizes the following products and tools to meet the security objectives of confidentiality, integrity, and availability.

F-PROT Professional for DOS based systems and DISINFECTANT for Macintosh based systems are the LMITCO standard anti-virus products; there are no products for other arenas.

S/Key is employed to provide one-time password capabilities for off-site access through a firewall to the INEL internal network.

Security software that is utilized within the security program includes Internet Security Scanner (ISS), Security Administrator Tool for Analyzing Networks (SATAN), Network Intrusion Detection (NID), and Security Profile Inspector (SPI) for VMS and UNIX. These tools are used within the security program and are not used on a company-wide basis.

Norton Utilities WIPEINFO is used on a company wide basis for sanitizing unclassified media; a Data Security, Inc. HD-2000 Bulk Degausser is used to degauss media as appropriate.

ACF2 and Natural Security provide host based security features on the IBM mainframe while MPEX3000, Security 3000, and VEAUDIT are utilized on HP3000 computers.

On Windows NT, the NTFS file structure provides file security and the NT operating system provides functional security. 


\section{SYSTEM MANAGEMENT}

\section{Overview}

System management tasks in the mainframe environment were driven by control. These include: configuration management, change control, performance monitoring, console management, problem management, and security. Desktop computing is managed by policy and user discipline. There are heterogeneous platforms, multiple software applications and various operating systems on the desktop. These machines have the ability to access data anywhere on the network. Access and control of the data is evolving into more of a user responsibility than an Information Resource Management (IRM) function.

In this environment, there are new functions that must be managed. These include: print services, maintaining user accounts, backup, and directory services. System management is the blending of traditional mainframe systems management tasks and the new network functions. Open System Foundation Distributed Management Environment (OSF DME) addresses these tasks.

Management of client/server computing is very new. As standards and products in this area evolve and stabilize, LMITCO will perform evaluations to determine which is the best fit for our computing environment. 
Appendix A 


\section{APPENDIX A}

\section{A. Hardware Platform}

\section{Hardware}

The recommended purchase configuration balances investment, requirements, and long-term usefulness. Individual user requirements may vary, and users should check the current company offerings for workstation purchases.

The approved configurations in June 1996 will be:

PC

Dell Pentium - 166 MHZ, 16 RAM, 1 GB-HD, 2 VRAM, 4X CDROM, 3COM, Sound, Tower, 17 ".26 pitch monitor.

\section{MAC \& UNIX}

There currently are no standard configurations identified for these platforms. 